\title{
Therapie der Mukoviszidose mit CFTR-Modulatoren
}

\author{
Treatment of Cystic Fibrosis with CFTR Modulators
}

Autor

Institut

\section{B. Tümmler}

Klinik für Pädiatrische Pneumologie, Allergologie und Neonatologie, Medizinische Hochschule Hannover und Standort BREATH des Deutschen Zentrums für Lungenforschung (DZL), Hannover eingereicht $\quad 31.12 .2015$

akzeptiert 12.1.2016

\section{Bibliografie}

DOI http://dx.doi.org/

10.1055/s-0042-100607

Online-Publikation: 19.2 .2016

Pneumologie 2016; 70: 301-313

(c) Georg Thieme Verlag KG

Stuttgart · New York

ISSN 0934-8387

\section{Korrespondenzadresse \\ Prof. Dr. med. Dr. rer. nat. \\ Burkhard Tümmler}

Klinik für Pädiatrische

Pneumologie

Allergologie und Neonatologie

OE 6710 Medizinische

Hochschule Hannover

Carl-Neuberg-Str. 1

30625 Hannover

tuemmler.burkhard@

mh-hannover.de

\section{Zusammenfassung \\ $\nabla$}

Die Mukoviszidose ist das erste Beispiel für die erfolgreiche Entwicklung einer Mutationstyp-spezifischen Therapie. Diese autosomal rezessiv vererbte Störung des epithelialen Transports von Chlorid und Bikarbonat wird durch Mutationen im CFTR-Gen ausgelöst. Zur Behandlung der ursächlichen Störungen werden zwei Klassen von CFTR-Modulatoren unterschieden. Potentiatoren erhöhen die Aktivität des mutanten Ionenkanals. Korrektoren überlesen irreguläre Stopp-Codons oder erleichtern die ko- und posttranslationale Prozessierung der CFTR-Mutante. In Deutschland sind zurzeit der Potentiator Ivacaftor zur Behandlung von Kanalöffnungsstörungen und der Korrektor Lumacaftor in Kombination mit Ivacaftor zur Therapie der häufigsten Mutante Phe508del CFTR zugelassen. Dieser Artikel gibt praktische Hinweise für die Anwendung der zugelassenen Modulatoren und informiert über die Populationsgenetik der CFTR-Mutationen in Deutschland, CFTR-Biomarker zur Erfolgskontrolle der Modulatortherapie und über die bisherige und aktuelle präklinische und klinische Forschung zur Entwicklung von CFTR-Modulatoren.

\section{Abstract \\ $\nabla$}

Personalized medicine promises that medical decisions, practices and products are tailored to the individual patient. Cystic fibrosis, an inherited disorder of chloride and bicarbonate transport in exocrine glands, is the first successful example of customized drug development for mutationspecific therapy. There are two classes of CFTR modulators: potentiators that increase the activity of CFTR at the cell surface, and correctors that either promote the read-through of nonsense mutations or facilitate the translation, folding, maturation and trafficking of mutant CFTR to the cell surface. The potentiator ivacaftor and the corrector lumacaftor are approved in Germany for the treatment of people with cystic fibrosis who carry a gating mutation such as p.Gly551Asp or who are homozygous for the most common mutation p.Phe508del, respectively. This report provides an overview of the basic defect in cystic fibrosis, the population genetics of CFTR mutations in Germany and the bioassays to assess CFTR function in humans together with the major achievements of preclinical research and clinical trials to bring CFTR modulators to the clinic. Some practical information on the use of ivacaftor and lumacaftor in daily practice and an update on pitfalls, challenges and novel strategies of benchto-bedside development of CFTR modulators are also provided.

\section{Einleitung}

$\nabla$

Die Mukoviszidose (syn. zystische Fibrose, CF) ist das häufigste schwere Erbleiden in Deutschland mit autosomal rezessivem Erbgang [1,2]. Diese generalisierte Erkrankung des exokrinen Epithels wird durch Mutationen im CFTR-Gen ausgelöst. Mangel oder Dysfunktion von CFTR führen zu Störungen der Sekretion von Chlorid, Bikarbonat und
Wasser in die Ausführungsgänge exokriner Drüsen. Die ins Drüsenlumen freigesetzten Muzine werden nicht korrekt gefaltet und hydratisiert, sodass sie ausfallen und die Drüsengänge verstopfen. Dieses mucus plugging löst die krankheitsbestimmenden Sekundärkomplikationen an Pankreas, Darm, Leber und Gallenwegen, Reproduktionstrakt und Atemwegen aus. Zudem ist im angesäuerten Milieu die Effizienz der primären 
Tab. 1 Populationsgenetik der häufigsten CF auslösenden Mutationen im CFTR-Gen bei deutschstämmigen Patienten (nach Gallati in [4]).

\begin{tabular}{|c|c|c|c|c|c|c|}
\hline $\begin{array}{l}\text { Alter Name } \\
\text { ('Legacy name') }\end{array}$ & $\begin{array}{l}\text { Neuer Name: } \\
\text { cDNA-Position }\end{array}$ & $\begin{array}{l}\text { Neuer Name: } \\
\text { Aminosäureposition }\end{array}$ & $\begin{array}{l}\text { Auswirkung auf CFTR } \\
\text { mRNA und Protein }\end{array}$ & $\begin{array}{l}\text { CFTR- } \\
\text { Lokalisation }\end{array}$ & $\begin{array}{l}\text { Mutations- } \\
\text { klasse; PI/PS }\end{array}$ & $\begin{array}{l}\text { Häufigkeit auf CF- } \\
\text { Chromosomen in \% }\end{array}$ \\
\hline $\begin{array}{l}\text { CFTRdele2,3 } \\
\text { (21kb) }\end{array}$ & $\begin{array}{l}\text { c.54-5940_273+ } \\
10250 \text { del21 kb }\end{array}$ & p.Ser18ArgfsX16 & Große Deletion & $11-\mathrm{E} 3$ & $\mathrm{I} ; \mathrm{PI}$ & 1,5 \\
\hline G85E & c. $254 G>A$ & p.Gly85Glu & Missense & E3, M1/MSD1 & II; PI & \\
\hline $\mathrm{R} 117 \mathrm{H}^{3}$ & c. $350 \mathrm{G}>\mathrm{A}$ & p.Arg117His & Missense & E4, MSD1 & III, IV; PS & $0,5(11,3)$ \\
\hline 1078delT & c.948delT & p.Phe316LeufsX12 & Frame-shift & E8(7), M5, MSD1 & $\mathrm{I} ; \mathrm{PI}$ & 0,6 \\
\hline R347P & c. $1040 G>C$ & p.Arg347Pro & Missense & E8(7), M6, MSD1 & IV; PI/PS & 1,0 \\
\hline $\begin{array}{l}\text { T5 polyT-Trakt } \\
\text { Variante }\end{array}$ & c. $1210-12 \mathrm{~T}[5]$ & - & Splice-Site & 19(8), NBD1 & V; PS & $0,5(12,2)$ \\
\hline F508del, $\Delta$ F508 & c.1521_1523 delCTT & p.Phe508del & Inframe & E11(10), NBD1 & II, (III, IV, VI); PI & 67,5 \\
\hline $1717-1 G>A$ & c. $1585-1 G>A$ & - & Splice-Site & I11(10), NBD1 & $\mathrm{I} ; \mathrm{PI}$ & 0,7 \\
\hline G542X & c. $1624 G>T$ & p.Gly542Ter & Nonsense & E12(11), NBD1 & $\mathrm{I} ; \mathrm{PI}$ & 1,6 \\
\hline G551D & c. $1652 G>A$ & p.Gly551Asp & Missense & E12(11), NBD1 & III; PI & 1,4 \\
\hline R553X & c. $1657 C>T$ & p.Arg553Ter & Nonsense & E12(11), NBD1 & $\mathrm{I} ; \mathrm{PI}$ & 1,8 \\
\hline 2143delT & c.2012delT & p.Leu671Ter & Frame-shift & $\mathrm{E} 14(13), \mathrm{R}$ & $\mathrm{I} ; \mathrm{PI}$ & 0,7 \\
\hline $2183 A A>G$ & c.2051_2052delAAinsG & p.Lys684SerfsX38 & Frame-shift & $\mathrm{E} 14(13), \mathrm{R}$ & $\mathrm{I} ; \mathrm{PI}$ & 0,6 \\
\hline 2184delA & c.2052delA & p.Lys684Asn fsX38 & Frame-shift & E14(13), R & $\mathrm{I} ; \mathrm{PI}$ & 0,5 \\
\hline 2184insA & c.2052_2053insA & p.Gln685ThrfsX4 & Frame-shift & E14(13), R & $\mathrm{I} ; \mathrm{PI}$ & 0,6 \\
\hline $2789+5 G>A$ & c. $2657+5 G>A$ & - & Splice-Site & $\begin{array}{l}\text { I16(14b), } \\
\text { M7/MSD2 }\end{array}$ & V; PS & 0,9 \\
\hline 2991del32 & $\begin{array}{l}\text { c.2859_2890delA } \\
\text { CATTCTGTTCTTCAAG } \\
\text { CACCTATGTCAACCC }\end{array}$ & p.Leu953PhefsX11 & Frame-shift & $\begin{array}{l}\text { E17(15), } \\
\text { M8/MSD2 }\end{array}$ & $\mathrm{I} ; \mathrm{PI}$ & 0,9 \\
\hline $3272-26 A>C$ & c. $3140-26 A>G$ & - & Splice-site & 120(17a), MSD2 & V; PS & 0,9 \\
\hline 3659delC & c.3528delC & p.Lys 1177 Ser fsX15 & Frame-shift & $\begin{array}{l}\text { E22(19), } \\
\text { M12/MSD2 }\end{array}$ & $\mathrm{I} ; \mathrm{PI}$ & 0,6 \\
\hline $3849+10 k b c>T$ & c. $3717+12191 C>T$ & - & Splice-Site & I22(19), NBD2 & V; PS & 0,7 \\
\hline W1282X & c. $3846 G>A$ & p.Trp1282Ter & Nonsense & E23(20), NBD2 & $\mathrm{I} ; \mathrm{PI}$ & 0,5 \\
\hline N1303K & c. $3909 C>C$ & p.Asn1303Lys & Missense & E24(21), NBD2 & II; PI & 1,7 \\
\hline
\end{tabular}

$\mathrm{E}=$ Exon, $\mathrm{I}=$ Intron, ()$=$ alte Nomenklatur, $\mathrm{M}=$ membranüberspannende Helix, MSD1/2=Transmembrandomäne $1 / 2$, NBD1/2=Nukleotidbindungsdomäne $1 / 2, \mathrm{R}=$ regulatorische Domäne

1 Die Häufigkeit der CFTR-Mutationen in der CF-Patientenpopulation in Deutschland ist dem Berichtsband ,Qualitätssicherung Mukoviszidose 2011، [3] entnommen.

${ }^{2}$ CF-Patienten sind exokrin pankreasinsuffizient (PI), wenn sie auf beiden CF-Chromosomen eine PI CFTR-Mutation tragen, CF-Patienten sind exokrin pankreassuffizient (PS), wenn sie auf einem oder beiden CF-Chromosomen einen PS CFTR-Mutation tragen.

3 Die Häufigkeit der Missense-Mutation R117H ist für Patienten mit CF und in Klammern für deutsche Männer mit CBAVD [62] angegeben. R117H ist entweder mit der 7T- (deutsche Probanden) oder der 5T-Variante (häufig bei Probanden mit irischer oder angelsächsischer Herkunft) des Polymorphismus der Spleißakzeptorstelle in Intron 9 gekoppelt. Compound heterozygote Personen für eine CF-auslösende Mutation und R117H-7T sind in der Regel gesund oder leiden an einer CFTR-assoziierten Erkrankung (Bronchiektasen, männliche Infertilität aufgrund kongenitaler beidseitiger Abwesenheit des Vas deferens: CBAVD) [62]. Compound Heterozygotie für eine CF-auslösende Mutation und R117H-5T führt typischerweise zu PS-CF oder einer CFTR-assoziierten Erkrankung.

${ }^{4}$ Die Häufigkeit des krankheitsassoziierten T5-Spleißpolymorphismus ist angegeben für CF-Patienten und in Klammern für deutsche Männer mit CBAVD [62].

Abwehr vermindert. Chronisch schwelende Atemwegsinfektionen sind die Folge, die bei den meisten Patienten Verlauf und Prognose der CF bestimmen.

Die Mukoviszidose ist erwachsen geworden. Dank kontinuierlich verbesserter symptomorientierter Therapieprogramme wird Neugeborenen mit CF derzeit eine Lebenserwartung von über 50 Jahren prognostiziert. In der ,Qualitätssicherung Mukoviszidose ' waren 2011 Daten von 4877 Patienten dokumentiert mit einem Anteil an Erwachsenen von 51,3\% [3]. Während die Zahl der Kinder und Jugendlichen mit CF in Zukunft annähernd konstant sein wird, erwarten wir in den kommenden 20 Jahren eine Verdopplung der Zahl an erwachsenen Patienten.

\section{CFTR und molekulare Pathologie der Mukoviszidose}

Der Anionenkanal CFTR setzt sich aus zwei membranüberspannenden Domänen (MSD1, MSD2), zwei zytosolischen Nukleotidbindungsfalten (NBD1, NBD2) und einer zytosolischen regulatorischen R-Domäne zusammen [1,4]. CFTR ist in der Apikalmembran der Epithelzelle lokalisiert. cAMP aktiviert den CFTR-Kanal, der unter Bindung und Hydrolyse von ATP geöffnet wird. Aufgrund von Mutationen im CFTR-Gen ist bei der Mukoviszidose die apikale Permeabilität für Chlorid und Bikarbonat vermindert. Mittlerweile sind mehr als 2000 Mukoviszidose auslösende Mutationen bekannt, die in sechs Mutationsklassen eingeteilt werden [1]. In Klasse I werden Mutationen zusammengefasst, bei denen die Synthese von CFTR-Protein fehlt oder gestört ist. Klasse II CFTR-Mutanten sind in Reifung und intrazellulärem Transport des CFTR-Proteins gestört. Bei Klasse III ist das Öffnen des CFTRIonenkanals defekt (sog. ,Gating-Mutationen'), und bei Klasse IV ist die Kanalleitfähigkeit verändert. Klasse-V-Mutationen umfassen Störungen, bei denen neben defektem CFTR noch geringe Mengen an normalem CFTR gebildet werden. Diese Mengen reichen aber nicht aus, um die Manifestation einer Mukoviszidose zu verhindern. Bei Klasse-VI-Mutanten wird das CFTR-Protein schneller abgebaut.

- Tab. 1 listet die CF-auslösenden Mutationen im CFTR-Gen auf, die auf mehr als 0,5\% der CF-Chromosomen von deutschstämmigen Mukoviszidosepatienten vorkommen [3,4]. Die Nomenklatur zur Bezeichnung der Mutationen wurde vor einigen Jahren umgestellt. Viele Leser werden mit dem ursprünglichen Namen 
(,Legacy Name') vertraut sein, aber nicht mit den neuen Bezeichnungen, die die CFTR cDNA-Sequenz als Referenz benutzen. - Tab. 1 informiert zusätzlich über die Lokalisation der Mutation in Gen und Protein, beschreibt den Mutationstyp und gibt die Mutationsklasse an. P.Gly551Asp ist beispielsweise eine Missense-Mutation, bei der in Exon 12 das Codon 551 für Glycin gegen Aspartat ausgetauscht ist. Asp551 CFTR ist eine in der NBD1 lokalisierte CFTR-Mutante, bei der die ATP-abhängige Öffnung des Ionenkanals gestört ist (Mutationsklasse III).

Die weltweit häufigste Störung, die drei Basen-Deletion p.Phe508del, kommt in Deutschland auf 67,5\% aller CF-Chromosomen vor [3,4]. Phe508del CFTR [5] ist ein temperaturlabiles fehlgefaltetes Protein, das größtenteils unmittelbar nach der Synthese am endoplasmatischen Retikulum wieder abgebaut wird (Klasse-II-Mutation). Nur ein kleiner Teil des neu synthetisierten Phe508del CFTR-Proteins erreicht die Apikalmembran der Epithelzelle. Die Kanalfunktion von Phe508del CFTR ist eingeschränkt (Klasse III und IV), und zusätzlich wird das thermolabile Phe508del CFTR schneller als normales CFTR abgebaut (Klasse VI).

Bei Patienten mit Migrationshintergrund wird ein anderes Mutationsspektrum beobachtet [4]. Insbesondere bei Konsanguinität, die bei türkischen und arabischen Familien nicht selten ist, sind die Patienten typischerweise homozygot für seltene Mutationen.

\section{CFTR-Biomarker zur Messung des Basisdefekts beim Mukoviszidosepatienten \\ $\nabla$}

Die Chloridpermeabilität der Apikalmembran der Epithelzelle ist die Zielgröße aller heutigen physiologischen Methoden, um eine CF oder eine CFTR-assoziierte Erkrankung zu diagnostizieren oder um den Einfluss eines CFTR-Modulators auf den Basisdefekt zu prüfen.

\section{Schweißtests}

Die Schweißdrüsen sind serös und unterliegen keinen Sekundärveränderungen, sodass unabhängig vom klinischen Schweregrad und Alter des Probanden der Basisdefekt der verminderten Chloridpermeabilität geprüft werden kann. Der Pilocarpin-Iontophorese-Schweißtest nach Gibson und Cooke [6] gilt weiterhin als Goldstandard zur Bestätigung oder zum Ausschluss der klinischen Verdachtsdiagnose Mukoviszidose. Der Test prüft die CFTR-abhängige Rückresorption von Chlorid aus dem Ausführungsgang der Schweißdrüse. Über Iontophorese des Parasympathikomimetikums Pilocarpin wird an einem kleinen Hautareal auf Arm oder Bein die Schweißproduktion stimuliert. Endschweiß wird über $30 \mathrm{~min}$ gesammelt und anschließend die Chloridkonzentration bestimmt. Chloridkonzentrationen von jeweils mehr als $60 \mathrm{mmol} / \mathrm{L}$ in mindestens zwei unabhängigen Untersuchungen bestätigen bei klinischem Verdacht und entsprechender Symptomatik die Diagnose einer CF. Chloridkonzentrationen von $30-60 \mathrm{mmol} / \mathrm{L}$ liegen im nicht aussagekräftigen Grenzbereich, bei einer Chloridkonzentration unter $30 \mathrm{mmol} / \mathrm{L}$ wird eine typische $\mathrm{CF}$ ausgeschlossen. Es gibt allerdings einige CFTR-Mutationen wie die Spleißmutation $3849+10 \mathrm{kbC}>\mathrm{T}$ (c.3717+12191C >T), die mit grenzwertigem oder sogar normalem Schweißchlorid einhergehen [4].

Das sekretorische Knäuel der Schweißdrüse setzt sich aus zwei Typen von sekretorischen Zellen zusammen. Der eine Zelltyp sezerniert plasmaisotonen Primärschweiß nach cholinerger Stimulation, der andere Zelltyp nach $\beta$-adrenerger Stimulation. Die
Schweißproduktion nach $\beta$-adrenerger Stimulation ist CFTR-abhängig. Dementsprechend sezernieren CF-Patienten nach Applikation eines $\beta$-Sympathikomimetikums gar keinen Schweiß, Probanden mit CFTR-assoziierten Störungen produzieren wenig Primärschweiß, und gesunde heterozygote CF-Genträger produzieren halb so viel Schweiß wie Kontrollpersonen [7]. Mittlerweile steht ein kliniktauglicher Test zur Verfügung, um mittels Evaporimetrie die primäre Schweißproduktion zu messen [8]. Der Test identifiziert alle Genträger einer CFTR-Mutation, selbst wenn mit dem Gibson-Cooke-Test grenzwertige oder normale Chloridkonzentrationen im Endschweiß gemessen werden.

\section{Messung der nasalen transepithelialen}

Potenzialdifferenz (NPD)

Im Zilien tragenden respiratorischen Epithel der Nasenschleimhaut wird die Chloridpermeabilität überwiegend von CFTR vermittelt. Die Ionenleitfähigkeit setzt sich aus einer mit Amilorid hemmbaren Natriumleitfähigkeit und einer Gluconat-sensitiven Chloridleitfähigkeit zusammen [9]. Ausfall oder Minderfunktion von CFTR äußern sich in einem elektronegativeren Basispotenzial, einer verstärkten Hyperpolarisation nach Blockade des Natriumkanals mit Amilorid und einer niedrigen oder ausbleibenden Depolarisation nach Gabe von Gluconat und Isoproterenol ( $\odot$ Abb.1a) [10]. Anhand von empirischen Scores, die die Antworten auf Amilorid und (Gluconat+Isoproterenol) verrechnen, lassen sich sensitiver als mit einem Gibson-Cooke-Schweißtest Probanden mit einer CFTR-Minderfunktion erkennen $[11,12]$. Gleichzeitig lässt sich mit Hilfe der NPD prüfen, ob ein CFTR-Modulator bei einem CF-Patienten den Basisdefekt der verminderten Chloridpermeabilität zu beeinflussen vermag.

\section{Ussing-Kammer-Messungen an der Rektum- schleimhautbiopsie (ICM)}

Die Messung der Ionenströme am Kolonepithel (ICM =, intestinal current measurement") wird ebenso wie die NPD eingesetzt, um bei nicht eindeutig interpretierbarem CFTR-Genotyp und/oder grenzwertigem Schweißtest zu prüfen, ob beim Probanden eine CFTR-Minderfunktion vorliegt oder nicht $[13,14]$. Die ICM ist gleichzeitig ein sensitiver und quantitativer Biomarker, um die Wirksamkeit eines CFTR-Modulators auf den CF-Basisdefekt zu erfassen.

Praktisches Vorgehen: Eine frisch gewonnene Schleimhautbiopsie wird in eine Ussingkammer eingespannt. Nach initialer Blockade der Aktivität von Natrium- und CFTR-Kanälen wird die Chloridsekretion hintereinander mit Carbachol, cAMP und Histamin stimuliert ( $\boldsymbol{O}$ Abb.2). Beim non-CF-Probanden dominieren CFTR-vermittelte Chloridströme ( $\bullet$ Abb.2a), während beim CFPatienten CFTR nicht oder nur in geringem Umfang zum Nettostrom beiträgt ( $\boldsymbol{O} \mathbf{A b b} . \mathbf{2 b}$ ). Die kumulative Antwort auf die Sekretagoga ist ein quantitatives Maß für die CFTR-Funktion im intestinalen Epithel [15].

Die Diagnostic Working Group der European Cystic Fibrosis Society hat ,Standard Operating Procedures' für die NPD und ICM veröffentlicht, um sicherzustellen, dass zertifizierte Zentren dieselben validierten Protokolle einsetzen. Zurzeit werden in Deutschland NPD und ICM von den CF-Zentren in Berlin, Bochum (nur NPD), Frankfurt (nur NPD), Gießen, Hannover, Heidelberg und Köln angeboten. 


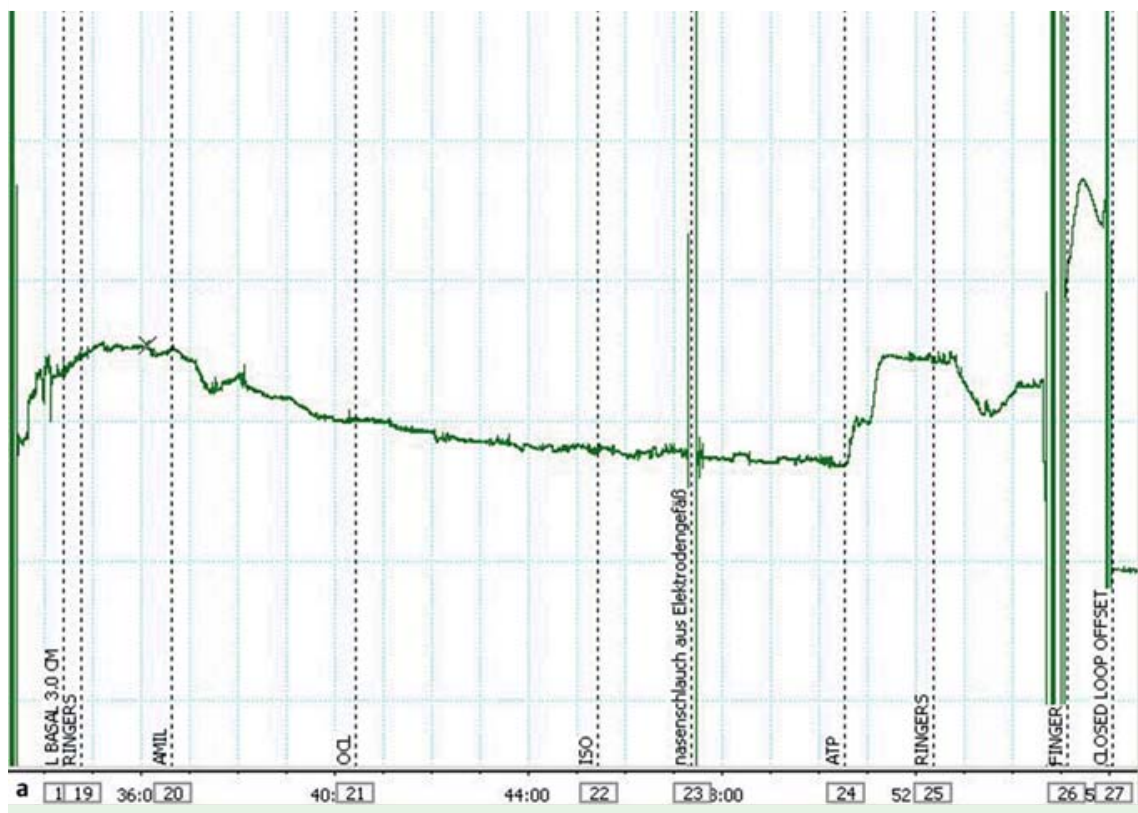

Abb. 1 Originalregistrierungen von Messungen der nasalen transepithelialen Potenzialdifferenz (NPD) von einem p.Gly551Asp compound heterozygoten Mukoviszidosepatienten (a) vor und (b) unter Therapie mit Ivacaftor und (c) einem weiteren p.Gly551Asp compound heterozygoten Mukoviszidosepatienten unter Therapie mit Ivacaftor. Alle Messungen wurden mit den gleichen Einstellungen durchgeführt. Entsprechend Protokoll wurde im Anschluss an die Eichmessungen das Potenzial registriert unter Superperfusion mit Ringer-Puffer (Basispotenzial), Amilorid-haltigem Puffer (Hyperpolarisation), chloridfreier Lösung ohne und dann mit Isoproterenol (Depolarisation), ATP und wieder Ringer-Lösung. Der Wechsel der Superfusionslösungen ist anhand der gestrichelten Linien zu erkennen. Registrierung Abb. 1 a zeigt ein stark elektronegatives Potenzial im CF-Bereich und ein hohes Hyperpolarisationssignal, das auch nach Zugabe von chloridfreier Lösung noch nicht beendet ist. Depolarisation als Zeichen einer CFTR-vermittelten Chloridpermeabilität wird nicht beobachtet. Das NPD-Profil in Abb. 1a entspricht einer typischen PI CF mit fehlender CFTR-vermittelter Chloridper-

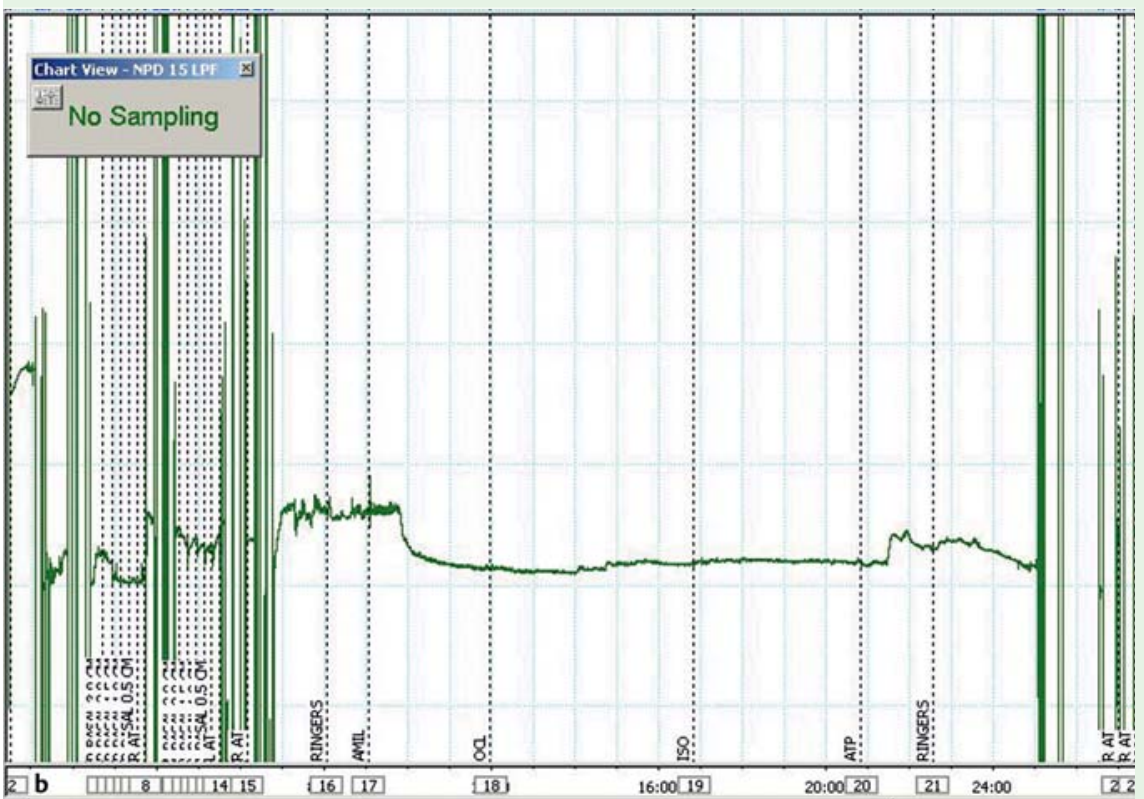
meabilität des respiratorischen Epithels. Unter Therapie mit Ivacaftor (Abb. $\mathbf{1}$ b) liegen Basispotenzial und Amiloridantwort im non-CF-Bereich. Ein niedriges Depolarisationspotenzial ist vorhanden, liegt aber weiterhin im CF-Bereich. Bei Unkenntnis der Behandlung mit einem CFTR-Modulator würde man das Profil in den Bereich PS CF/CFTR-RD einordnen.

Primäre intestinale Organoide

Aus den Rektumschleimhautbiopsien lassen sich Krypten isolieren, die in speziellen Kulturmedien zu stammzellhaltigen Organoiden differenzieren [16]. Organoide lassen sich wöchentlich subkultivieren und in einem Cocktail aus Stammzell-Erhaltungsfaktoren mindestens über 1,5 Jahre passagieren. Zudem können Organoide eingefroren und bei Bedarf erneut kultiviert werden. Nach Zugabe von Forskolin werden die CFTR-Kanäle des Organoids aktiviert, was sich mikroskopisch anhand der Schwellungskinetik der Organoide quantitativ verfolgen lässt. Somit steht ein patientenspezifischer Bioassay zur Verfügung, um das individuelle Ansprechen auf CFTR-Modulatoren zu testen. In der Tat wurde in Abhängigkeit vom Spender eine große Bandbreite der Antworten Phe508del homozygoter CF-Organoide auf die Gabe von CFTR-Potentiatoren und -Korrektoren beobachtet [17].

\section{Präklinische und klinische Entwicklung von Mutations- typ-spezifischen Therapien der Mukoviszidose \\ $\nabla$}

\section{Korrektur von Stopp-Mutationen}

Stopp-Mutationen wie p.Arg553Ter oder p.Gly542Ter kommen auf $5 \%$ der CF-Chromosomen vor [4]. Wenn ein mutiertes CFTRGen mit einem solchen vorzeitigen Stopp-Codon (PTC=,premature termination codon') transkribiert wird, wird das neu gebildete mRNA-Transkript umgehend wieder abgebaut (NMD=,nonsense mediated decay ${ }^{c}$ ), oder die Proteinbiosynthese wird am Ribosom vorzeitig beendet [18]. Dieser vorzeitige Stopp der Translation ließe sich verhindern, wenn das Stopp-Codon vom Ribosom überlesen wird und stattdessen eine Aminosäure in das naszierende Protein eingebaut wird. Aminoglykoside binden an das prokaryotische und eukaryotische Ribosom. In Eukaryonten wird die bei der Paarung von Codon und Anticodon auftretende Konformationsänderung der ribosomalen RNA verändert, sodass an einem Stopp-Codon der Einbau einer anderen Aminosäure toleriert wird $[18,19]$. 

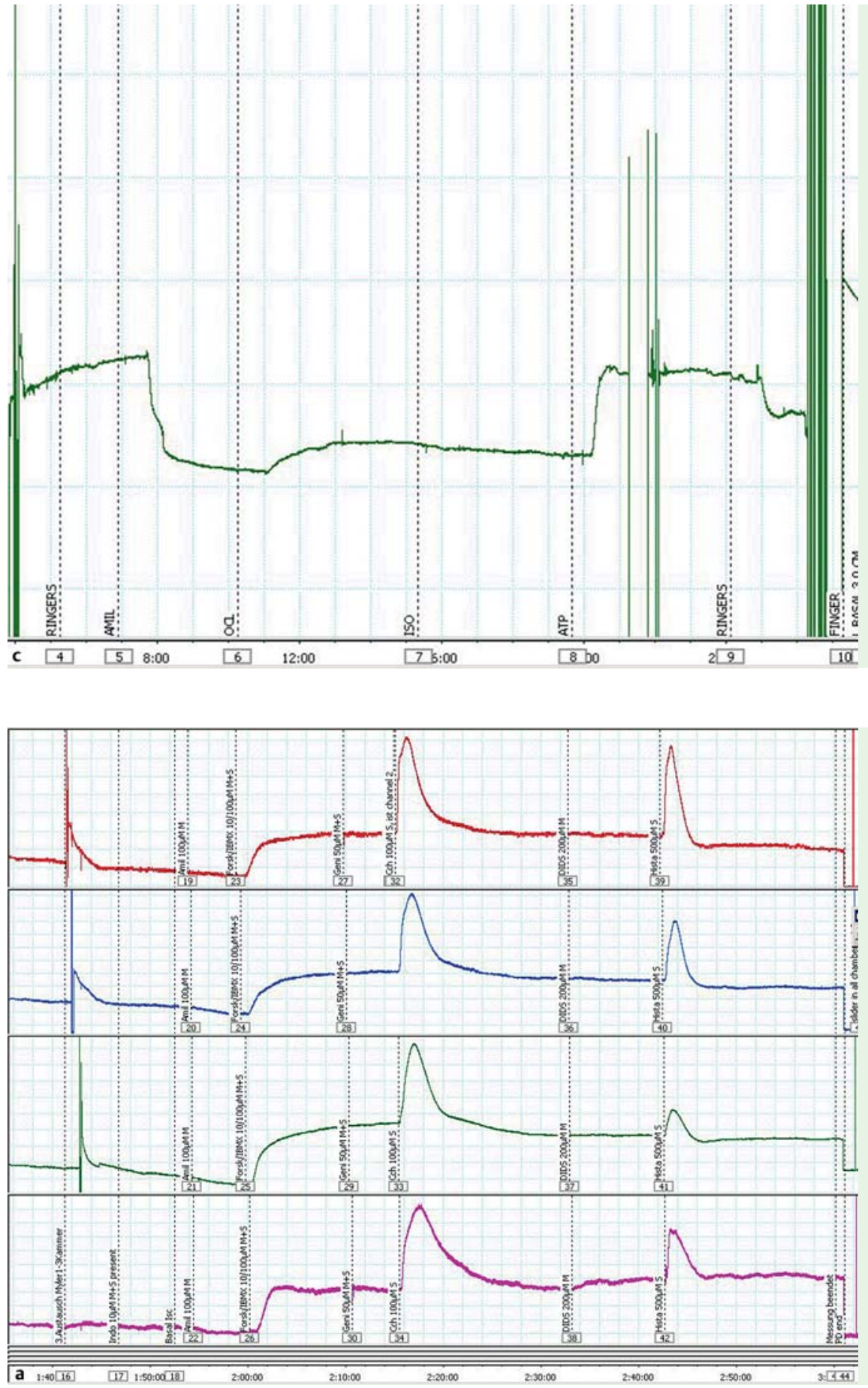

Bei dem anderen Patienten (Abb.1 c) wurden unter Therapie mit Ivacaftor Basis- und Depolarisationspotenziale im Übergangsbereich zwischen CF und non-CF gemessen. Die NPD-Messungen wurden gemäß SOP NPD_EU001 (Version 1.7, März 2013) der European Cystic Fibrosis Society Diagnostic Network Working Group durchgeführt.
Effizienter als Aminoglykoside wirkt der Stoff Ataluren (PTC124) [20]. Ataluren bindet an die 28S rDNA des eukaryontischen Ribosoms und fördert das Überlesen von PTCs, ohne das reguläre Stopp-Codon zu beeinflussen. Die normale Proteinbiosynthese wird somit von Ataluren nicht beeinträchtigt.

Phase-II-Studien an CF-Patienten mit Stopp-Mutationen wurden in Israel, Frankreich und den USA durchgeführt. Sowohl bei Erwachsenen (Studie in Israel) als auch bei Kindern (Studie in Frankreich) kam es unter der Gabe von Ataluren zu einer signifikanten Erhöhung des Depolarisationspotenzials in der NPD $[21,22]$. Ataluren dürfte somit die CFTR-vermittelte Chloridleitfähigkeit des respiratorischen Epithels aktiviert haben. Bei der anschließenden Phase-III-Studie an 238 CF-Patienten wurde al-
Abb. 2 Originalregistrierungen von Messungen der Kurzschlussströme an Rektumschleimhautbiopsien in der Mini-Ussing-Kammer von (a) einem gesunden non-CF-Probanden und einem p.Gly551Asp/p.Phe508del compound heterozygoten CF-Patienten (b) vor und (c) unter Therapie mit Ivacaftor. Vier Biopsien wurden jeweils simultan in 4 Kammern gemessen. Nach Äqulibrierung der Biopsien in Meyler-Puffer und Test der Vitalität werden der Natriumkanal mit Amilorid und die Prostaglandin-vermittelte Synthese von cAMP mit Indomethacin geblockt. Anschließend werden Kaliumströme und Chloridströme hintereinander durch Forskolin/IBMX, Carbachol und Histamin aktiviert. Der Zeitpunkt der Zugabe der Pharmaka ist anhand der gestrichelten Linien zu erkennen. Beim gesunden non-CF-Probanden (Abb. 2a) sind die Chloridströme stärker als die Kaliumströme, und es werden daher unimodale Antworten von apikalen Chloridauswärtsströmen beobachtet. Im intestinalen Epithel wird Chlorid nahezu ausschließlich von CFTR sezerniert. lerdings kein Unterschied zwischen Verum und Placebo in der Zahl pulmonaler Exazerbationen und der 1-Sekundenkapazität FEV1 beobachtet [23]. Eine anschließende post-hoc Analyse an Patienten, die nicht mit dem Aminoglykosid Tobramycin als KoMedikation inhaliert hatten, zeigte allerdings einen signifikanten Behandlungseffekt. In der mit Ataluren behandelten Gruppe waren im Beobachtungszeitraum von 48 Wochen weniger pulmonale Exazerbationen aufgetreten (1,42 Ereignisse [0, 9-1,9] vs. 2,18 Ereignisse $[1,6-2,7] ; \mathrm{p}=0,0061$ ) und die FEV1 (\% des Solls) war um 5,7\% höher (95\% CI 1,5-10,1). Die Sicherheitsprofile waren unter Ataluren und Placebo vergleichbar, allerdings wurde bei 18 (15\%) der 118 CF-Patienten der Verumgruppe eine er- 


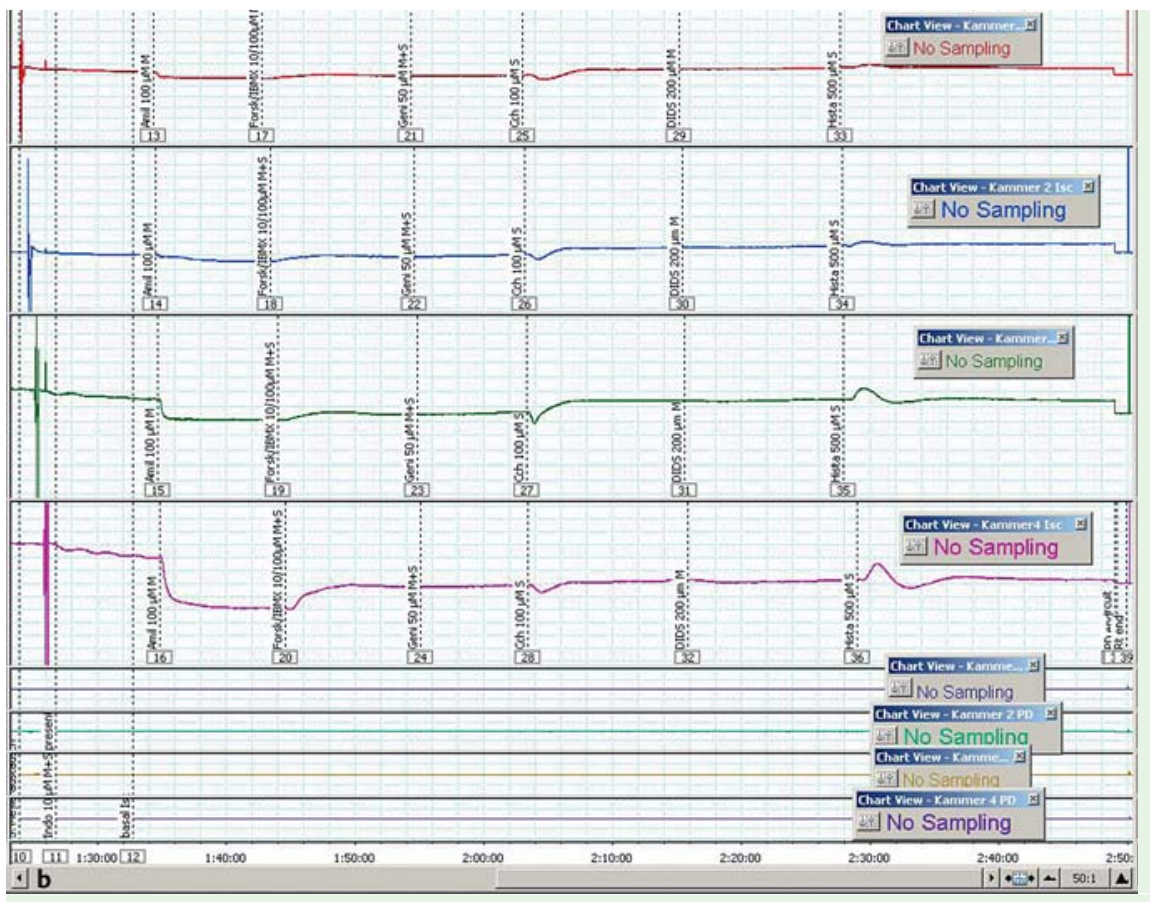

Beim CF-Patienten mit dem CFTR-Genotyp p.Gly551Asp/p.Phe508del wurde vor Beginn der Behandlung mit Ivacaftor in der ICM (Abb. 2b) eine geringe endogene CFTR-vermittelte Chloridsekretion beobachtet, was man an der Antwort auf Forskolin/IBMX und den bimodalen Antworten auf Carbachol und Histamin erkennen kann. Diese residuelle CFTR-Aktivität beträgt bei p.Gly551Asp/p. Phe508del Genotyp im Mittel 10\% der CFTR-Aktivität von non-CF-Kontrollen [35].

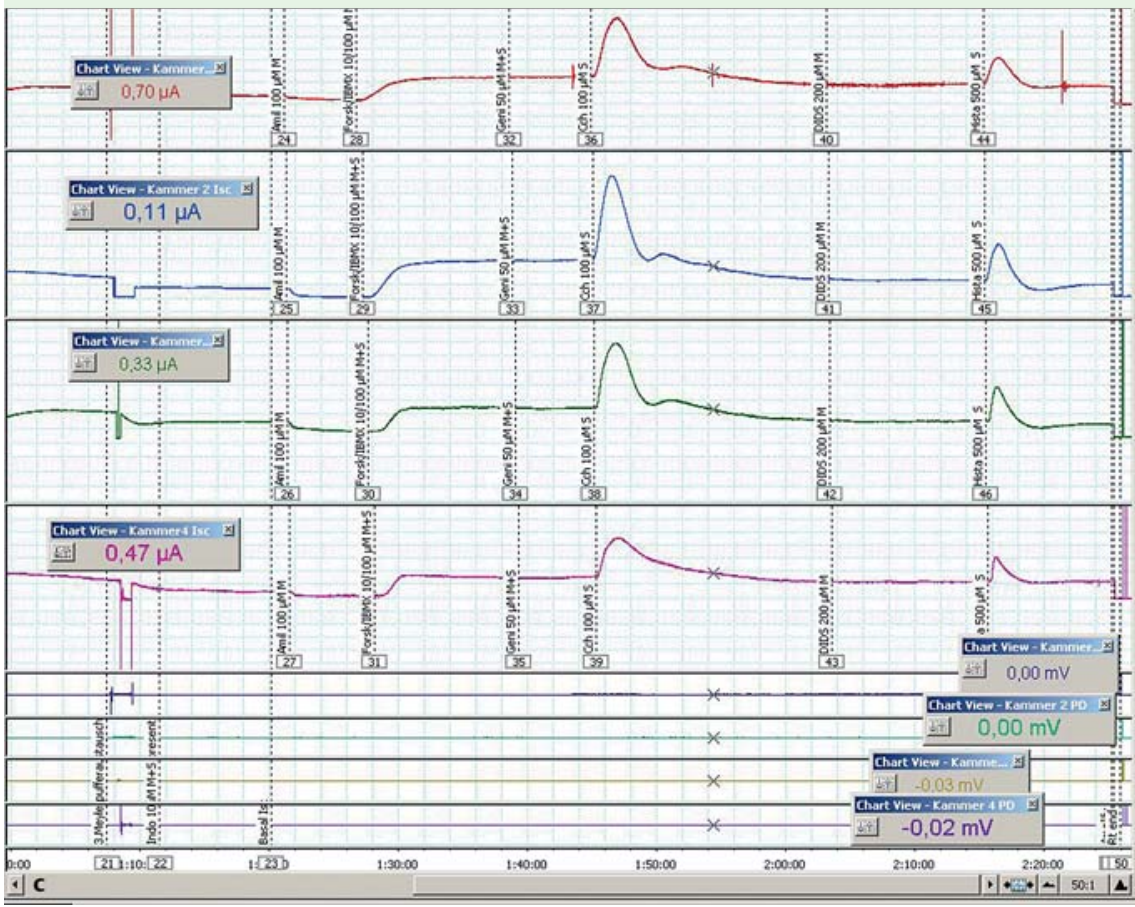

Unter Therapie mit Ivacaftor (Abb. 2c) wurde von diesem Patienten ein normales Chloridsekretionsprofil in der ICM gemessen. Dieser Proband gehört zu der Gruppe von 12 Patienten, an denen die Normalisierung der CFTR-vermittelten Chloridsekretion durch Ivacaftor in vivo nachgewiesen wurde [35]. Die ICM-Messungen wurden gemäß SOP ICM_EU001 (Version 2.7, Oktober 2011) der European Cystic Fibrosis Society Diagnostic Network Working Group durchgeführt.

höhte Serumkreatininkonzentration gemessen, was als akute Nierenschädigung zu interpretieren ist [23].

PTC Therapeutics hat eine weitere Phase-III-Studie zur Wirksamkeit von Ataluren bei CF-Patienten mit Stopp-Mutationen aufgelegt. In diese Studie werden nur Patienten ab einem Alter von 6 Jahren eingeschlossen, die kein Aminoglykosid inhalieren. Primärer Endpunkt ist die relative Veränderung der 1-Sekundenkapazität FEV1.Aus Deutschland beteiligen sich CF-Zentren aus Berlin, Bochum, Frankfurt, Jena, Köln und München an dieser internationalen Studie.

\section{CFTR-Potentiatoren}

CFTR-Potentiatoren erhöhen die epitheliale Sekretion von Chlorid und Bikarbonat, indem sie die Frequenz der Kanalöffnungen und/oder die Kanalöffnungszeiten erhöhen. Eine Monotherapie mit Potentiatoren ist somit für Mukoviszidosepatienten mit Klasse-III-, Klasse-IV- oder Klasse-V-Mutationen prinzipiell geeignet.

Flavone, Xanthine und Benzimidazole wurden als CFTR-Potentiatoren in vitro charakterisiert, aber allein das Flavon Genistein besitzt eine hinreichend hohe Affinität zu CFTR, dass ein Einsatz beim Menschen erfolgversprechend wäre [24]. Deshalb wurden in den letzten 20 Jahren Millionen von Natur- und synthetischen Stoffen in Hochdurchsatzverfahren daraufhin getestet, ob sie die CFTR-Aktivität erhöhen können. Eines dieser Moleküle namens 


\begin{tabular}{|c|c|c|c|c|c|}
\hline Studie & $\begin{array}{l}\text { Accurso et al. } \\
\text { (2010) [29] }\end{array}$ & $\begin{array}{l}\text { Ramsey et al. } \\
\text { (2011) [30] }\end{array}$ & $\begin{array}{l}\text { Davies et al. } \\
\text { (2013) [31] }\end{array}$ & $\begin{array}{l}\text { Davies et al. } \\
\text { (2013) [32] }\end{array}$ & \multirow{14}{*}{$\begin{array}{l}\text { Tab. } 2 \text { Überblick über ausge- } \\
\text { wählte klinische Studien mit Iva- } \\
\text { caftor CF-Patienten mit mindes- } \\
\text { tens einem p.Gly551Asp CFTR- } \\
\text { Allel. }\end{array}$} \\
\hline Einschlussalter & $>18$ Jahre & $>12$ Jahre & 6-11 Jahre & $>6$ Jahre & \\
\hline Zahl der Studienteilnehmern & 39 & 167 & 56 & 21 & \\
\hline Studiendauer & 28 Tage & 48 Wochen & 48 Wochen & 12 Wochen $^{1}$ & \\
\hline Dosierung von Ivacaftor & $\begin{array}{l}25,75,150 \\
250 \mathrm{mg} \text { bd }\end{array}$ & $150 \mathrm{mg}$ bd & $150 \mathrm{mg}$ bd & $150 \mathrm{mg}$ bd & \\
\hline \multicolumn{5}{|l|}{ Differenz Verum - Placebo ${ }^{2}$} & \\
\hline absolute Änderung in FEV1 \% d. Solls & & $10,6 \%$ & $10,0 \%$ & $8,7 \%$ & \\
\hline relative Änderung in FEV1 \% d. Solls & $8,7 \%$ & $17,0 \%$ & $12,8 \%$ & $16,6 \%$ & \\
\hline $\begin{array}{l}\text { relatives Risiko einer pulmonalen } \\
\text { Exazerbation }\end{array}$ & & 0,46 & & & \\
\hline Änderung im LCl & & & & -2.2 & \\
\hline 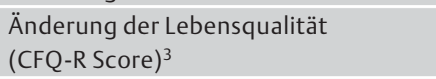 & 8,3 Punkte & 8,6 Punkte & 5,1 Punkte & 4,0 Punkte & \\
\hline Zunahme des Körpergewichts & & $2,7 \mathrm{~kg}$ & $2,8 \mathrm{~kg}$ & & \\
\hline Abnahme des Endschweißchlorids & $-59 \mathrm{mmol} / \mathrm{L}$ & $-48 \mathrm{mmol} / \mathrm{L}$ & $-54 \mathrm{mmol} / \mathrm{L}$ & $-48 \mathrm{mmol} / \mathrm{L}$ & \\
\hline Depolarisationspotenzial in NPD ${ }^{4}$ & $-12 m V$ & & & & \\
\hline
\end{tabular}

Ivacaftor wurde von der Firma Vertex bis zur Zulassung entwickelt [25].

Ivacaftor (IUPAC Name N-(2,4-di-tert-butyl-5-hydroxyphenyl)4-oxo-1,4-dihydroquinolin-3-carboxamid) bindet direkt an CFTR. Die Öffnung des CFTR-Anionenkanals verlangt normalerweise die Bindung und Hydrolyse von ATP. In Anwesenheit von Ivacaftor wird der CFTR-Kanal ATP-unabhängig geöffnet, und die Kanalöffnungszeit wird verlängert $[25,26]$. Unter Ivacaftor wird bei allen Mutationen, bei denen die Kanalöffnung defekt ist, eine Kanalöffnungswahrscheinlichkeit von $30 \%$ bis $118 \%$ des Wildtyp CFTR-Kanals erreicht [27]. Ivacaftor ist aber nicht nur bei den Typ III ,Gating'-Mutationen wirksam, sondern auch bei vielen anderen Missense-Mutationen. Von 54 in der Zellkultur getesteten CFTR-Missense-Mutationen konnte bei 38 Mutanten der CFTRKanal aktiviert werden, wobei bei 26 Mutanten eine klinisch relevante Aktivierung von mehr als 10\% des CFTR-Wildtyps erzielt wurde [28].

Die häufigste Typ III ,Gating'-Mutation ist p.Gly551Asp CFTR. Deshalb wurden klinische Studien in der Anfangsphase an CF-Patienten durchgeführt, die auf mindestens einem CF-Allel p.Gly551Asp CFTR tragen. Alle klinischen Phase-II- und -III-Studien erzielten unabhängig von der aktuellen Schwere der CF-Erkrankung beeindruckende Verbesserungen von Lebensqualität, Lungenfunktion und Anthropometrie ( $\bullet$ Tab.2) [29-32]. Die 1-Sekundenkapazität nahm binnen eines Monats im Mittel um 10 absolute Prozentpunkte zu, und die Frequenz pulmonaler Exazerbationen halbierte sich. Der Zugewinn an FEV1 blieb bei p.Gly551Asp CFTR compound heterozygoten CF-Patienten über die gesamte Studiendauer erhalten. Bei den p.Gly551Asp CFTR homozygoten CF-Patienten wurde sogar eine kontinuierliche Zunahme der FEV1 beobachtet [33]. Auch bei schwerkranken CF-Patienten mit einer FEV1 von weniger als $40 \%$ des Solls wurden absolute Verbesserungen der FEV1 um 4-5 Prozentpunkte erzielt [34].

Bei Patienten mit altersnormaler Spirometrie (FEV1 $>90 \%$ des Solls) wurde nicht nur eine weitere Verbesserung von FEV1 und FVC beobachtet, sondern darüber hinaus ließ sich der zu Studienbeginn pathologisch erhöhte ,Lung clearance index ( $\mathrm{LCI}$ ) im Mittel um 2,2 Punkte in den Normalbereich verschieben [32]. Ein erhöhter LCI als Maß der Ventilationsinhomogenität ist das frü- heste Symptom der CF-Lungenerkrankung und beruht auf der Mucusobstruktion der Atemwege. Diese Daten legen nahe, dass eine Mutationstyp-spezifische Therapie möglichst früh, also bereits während der klinisch asymptomatischen Phase begonnen werden sollte.

Die Mucusobstruktion der Atemwege ist eine direkte Folge des Basisdefekts der verminderten Sekretion von Chlorid und Bikarbonat. Ein Rückgang des LCI sollte also eine Verbesserung der CFTR-Funktion widerspiegeln. In der Tat konnte bei den klinischen Studien ein spektakulärer Einfluss von Ivacaftor auf die CFTR-Biomarker nachgewiesen werden. Unter Ivacaftor reduzierte sich die Chloridkonzentration im Schweißtest von Werten im klassischen CF-Bereich um $100 \mathrm{mmol} / \mathrm{L}$ in den Grenz- oder sogar in den Normalbereich ( Tab.2) [29-32]. Das CFTR-assoziierte Depolarisationspotenzial in der NPD normalisierte sich bei den meisten Probanden ( $\mathbf{A b b} \mathbf{1} \mathbf{1}$ b, c) [29], und in der ICM wurden Chloridströme im Normalbereich gemessen ( Abb.2c) [35]. Aktivierung von CFTR mit cAMP induzierte eine intestinale Chloridsekretion von 52\% des Durchschnittswerts gesunder non-CFKontrollen. Ivacaftor ist somit der erste CFTR-Modulator, der bei einer Subgruppe von Mukoviszidosepatienten den Basisdefekt korrigiert.

Schon 2,5 Jahre nach Zulassung durch die FDA wurde 2014 über weitere Effekte der Therapie mit Ivacaftor auf das CF-Krankheitsbild berichtet [36]. Neben den bereits aus den klinischen Studien bekannten Verbesserungen von Lungenfunktion und Gewicht wurde über einen Rückgang stationärer Aufenthalte, eine Verbesserung der mukoziliären Clearance und einen Rückgang des Nachweises des pathognomonischen Keims Pseudomonas aeruginosa in respiratorischen Sekreten berichtet. Das gastrointestinale $\mathrm{pH}$ hatte sich normalisiert und der insulinpflichtige Typ III CF Diabetes mellitus hatte sich zurückgebildet. Fazit: Ivacaftor hat sich bei CF-Patienten mit mindestens einem p.Gly551Asp CFTRAllel als wirksamer CFTR-Modulator erwiesen. Der Zugewinn an Lebensqualität ist beträchtlich.

Ivacaftor moduliert nicht nur Asp551 CFTR, sondern generell Typ III ,Gating-Mutationen. Eine klinische Studie an neun seltenen Typ-III-Mutationen zeigte ähnliche Verbesserungen in FEV1, Anthropometrie, Schweißchlorid und Lebensqualität wie bei 
p.Gly551Asp CFTR [37]. Ein differenzierteres Bild ergab sich bei der klinischen Prüfung von Ivacaftor an CF-Patienten mit mindestens einem p.Arg117His Allel [38]. Diese Mutation besitzt Typ-III- und Typ-IV-Charakteristika und ist im CFTR-Gen entweder mit der T7- oder der T5-Variante des Spleißpolymorphismus in Intron 9 vergesellschaftet ( $\bullet$ Tab. 1). Genträger für eine CFauslösende Mutation und p.Arg117His-7T sind in der Regel gesund oder sind von einer CFTR-assoziierten Erkrankung (CFTRRD) wie Bronchiektasen oder CBAVD betroffen, während Genträger für eine CF-auslösende Mutation und p.Arg117His-5T entweder an einer CFTR-RD oder einer mild ausgeprägten Mukoviszidose mit exokriner Pankreassuffizienz erkrankt sind. In der Phase-III-Studie wurde unter der Gabe von Ivacaftor bei den Probanden mit p.Arg117His CFTR eine signifikante Reduktion der Chloridkonzentration im Schweißtest um im Mittel $24 \mathrm{mmol} / \mathrm{l}$ beobachtet, d.h. der CF-Basisdefekt wurde abgeschwächt. Dieser Effekt auf den CFTR-Biomarker ging aber nicht mit einer signifikanten Besserung der Lungenfunktion einher. Nur bei der Subgruppe der erwachsenen Genträger des p.Arg117His-5T Allels wurde im Vergleich zu Placebo eine Erhöhung der FEV1 um absolut 5 Prozentpunkte beobachtet. Dieses Ergebnis legt nahe, dass im Fall von sog. ,milden' CFTR-Mutationen mit unklarem Krankheitswert die Gabe eines CFTR-Modulators nur bei symptomatischen Probanden von klinischem Nutzen ist. Beim symptomfreien Probanden ohne CF-spezifische Auffälligkeiten in der Vorgeschichte ist die Indikation zur Behandlung mit einem CFTR-Modulator nur nach sorgfältiger Evaluation des Einzelfalls zu stellen und anschließend regelmäßig zu überprüfen.

\section{CFTR-Korrektoren}

Knapp 90\% der deutschen CF-Patienten tragen die 3-Basen-Deletion p.Phe508del auf einem oder beiden CF-Chromosomen. Die Phe508del CFTR-Mutante zeigt Typ-II-, -III-, -IV- und -VI-Anomalien; der Phänotyp wird aber in erster Linie vom Typ II der defekten posttranslationalen Prozessierung bestimmt [5]. Während der Synthese am endoplasmatischen Retikulum bildet sich eine temperaturlabile Konformation aus, die zu sofortiger Ubiquitinylierung und Abbau im Proteasom disponiert. Aus immunchemischen Untersuchung an Biopsien und operativ entferntem Gewebe von p.Phe508del homozygoten Patienten wissen wir, dass Phe508del CFTR im Vergleich zum non-CF-Wildtyp in Mengen von 0 - 20\% (im Mittel 4\%) im Respirations- und Gastrointestinaltrakt vorliegt $[39,40]$. Die vergleichsweise sehr geringen Mengen an apikalem und korrekt prozessiertem Phe508del CFTR sind klinisch bedeutsam, da bei den wenigen Indexfällen mit mehr als $10 \%$ CFTR-Restfunktion ein milderer Verlauf der CF beobachtet wurde [40].

In der Zellkultur lässt sich durch Wachstum bei Temperaturen unter $28^{\circ} \mathrm{C}$ oder Zugabe von Chaperonen oder anderen Faltungshelfern das neu synthetisierte Phe508del CFTR in eine Konformation überführen, die eine weitgehend normale Reifung und Prozessierung durchläuft [5, 41]. Beim Hochdurchsatzscreening hat man bereits zahlreiche Korrektoren identifiziert, aber bisher wurde nur eine einzige Substanz namens Lumacaftor sowohl im Labor als auch in klinischen Studien eingehend charakterisiert [42-45].

Der von der Firma Vertex entwickelte Korrektor Lumacaftor stabilisiert kritische intramolekulare Wechselwirkungen zwischen Nukleotidbindungsfalte 1 und Cytosol-exponierten Modulen der Transmembrandomänen [41]. In Anwesenheit von Lumacaftor wird Phe508del CFTR in die reife Isoform überführt und wird über den Golgi-Apparat zur Apikalmembran transportiert [42].
Phe508del CFTR verbleibt allerdings in einer temperaturlabilen Konformation [46].

In einer Phase-II-Studie wurde die Monotherapie von p.Phe508del homozygoten CF-Patienten mit Lumacaftor geprüft [43]. Dosisabhängig verminderte sich die Chloridkonzentration im Schweißtest um maximal $8 \mathrm{mmol} / \mathrm{l}$ bei der höchstens Einmaltagesdosis von $200 \mathrm{mg}$, aber Lungenfunktion und NPD zeigten keinen Unterschied im Vergleich zu Placebo. Angesichts der ausgebliebenen klinischen Effizienz wurde als nächstes in einer weiteren PhaseII-Studie geprüft, ob die Kombination des Korrektors Lumacaftor mit dem Potentiator Ivacaftor bessere Ergebnisse zeitigt. Unter der Kombinationstherapie wurde in der Tat in den Subgruppen eine größere Abnahme des Schweißchlorids um bis zu $10 \mathrm{mmol} /$ L und eine Zunahme der FEV1 um 5 bis 8 Prozentpunkte beobachtet [44]. Diese Daten ermutigten den Sponsor, die weltweit bislang größte klinische Studie an Mukoviszidosepatienten durchzuführen [45]. 1108 p.F508del homozygote Patienten aus über 200 CF-Ambulanzen wurden für zwei randomisierte doppelblinde Placebo-kontrollierte Phase-III-Studien rekrutiert. Die Studienteilnehmer erhielten entweder zweimal täglich je 250 mg Ivacaftor und $400 \mathrm{mg}$ Lumacaftor (A) oder zweimal täglich $250 \mathrm{mg}$ Ivacaftor und $600 \mathrm{mg}$ Lumacaftor (B) oder Placebo. Unter dem Behandlungsarm A verbesserte sich die FEV1 im Vergleich zu Placebo absolut um 2,8\% und relativ um 4,8\% und unter dem Behandlungsarm B um 3,3\% bzw. 5,6\%. Dieser Zugewinn an FEV1 wurde unabhängig von Alter, Geschlecht, Ausgangslungenfunktion und Ko-Medikation beobachtet. Allerdings war die Bandbreite im Ansprechen sehr groß. Bei ca. 20\% der Studienteilnehmer hatte die FEV1 absolut um $8 \%$ und mehr zugenommen, während sich die FEV1 bei mehr als einem Drittel nicht signifikant verbessert hatte. Zusätzlich wurde eine Zunahme des Body Mass Index um 0,24 (A) bzw. 0,28 (B) und eine Reduktion pulmonaler Exazerbationen um 30\% (A) bzw. 20\% (B) gesehen. In der anschließenden Roll-Over-Studie, bei der alle Teilnehmer Studienmedikation erhielten, reproduzierten die Probanden, die vorher Placebo erhalten hatten, die Studienergebnisse der Teilnehmer aus den Verum-Armen.

Als die Studienergebnisse im Mai 2015 veröffentlicht wurden [45], war die Reaktion der Fachöffentlichkeit weniger enthusiastisch als nach den Publikationen über die Wirksamkeit von Ivacaftor bei Patienten mit p.Gly551Asp-Mutation in den Jahren zuvor. Pamela Davis schrieb in ihrem Editorial im New England Journal of Medicine [47]:

The combination of lumacaftor and ivacaftor produced significant improvements in lung function and weight gain, as well as significant amelioration of respiratory symptoms and pulmonary exacerbations. However, the extent of improvement was not as great as that produced by ivacaftor alone in the treatment of patients with the Gly551Asp mutation. The forced expiratory volume in 1 second $\left(F E V_{1}\right)$ increased by only about 3 percentage points, as compared with 11 percentage points with ivacaftor alone in patients with the Gly551Asp mutation. To put these changes in context, approximately the same relative improvement was seen when inhaled DNase was introduced into the cystic fibrosis treatment armamentarium, and greater improvement, about $10 \%$ of baseline $F E V_{1}$, was seen with inhaled tobramycin, although neither drug addresses the basic defect in the protein.

Ähnlich kritisch äußerten sich Andrew Jones und Peter Barry in THORAX [48]:

... the improvements in lung function seen in the study are modest at best, and considerably less than those for ivacaftor in patients with Gly551Asp mutation. This lack of enthusiasm does not solely 
represent an elevated sense of expectation following the initial experience with ivacaftor as the improvements in $\% F E V_{1}$ are similar to those previously witnessed for a number of other treatments currently available that address the downstream consequences of CFTR dysfunction, such as DNAase, azithromycin and nebulised antibiotics. Similarly, the reduction in pulmonary exacerbations is not an outlier when grouped with other pre-modulation therapies, a fact even more notable given the relatively low uptake of chronic azithromycin therapy in this cohort (61.4\%).

Fazit mit den Worten des Autors [49]: It is a stony road to F508del CFTR pharmacotherapy. We have just smoothed the first rock.

\section{Umgang mit zugelassenen CFTR-Modulatoren in der Praxis \\ $\nabla$}

Ataluren (Handelsname Translarna ${ }^{\mathrm{TM}}$ ) ist in der EU zur Behandlung der Muskeldystrophie Duchenne ab einem Alter von 5 Jahren zugelassen, wenn die Patienten eine Stopp-Mutation in ihrem $D M D-G e n$ tragen. Die FDA hat Ataluren den ,orphan drug، Status zur Behandlung von CF-Patienten mit Stopp-Mutationen zuerkannt.

Ivacaftor (Handelsname Kalydeco ${ }^{\mathrm{TM}}$ ) ist in Deutschland laut Fachinformation (Stand 31.12.2015) zugelassen zur Behandlung von Patienten mit Mukoviszidose ab 2 Jahren, die eine der folgenden Gating-Mutationen (Klasse III) im CFTR-Gen aufweisen: p.Gly551Asp, p.Gly1244Glu, p.Gly1349Asp, p.Gly178Arg, p.Gly551Ser, p.Ser1251Asn, p.Ser1255Pro, p.Ser549Asn oder p.Ser549Arg.

Ivacaftor kann außerdem zur Behandlung von CF-Patienten ab 18 Jahren verordnet werden, bei denen eine p.Arg117His-Mutation im CFTR-Gen vorliegt; allerdings sollte nach Meinung des Autors die Indikation bei jedem p.Arg117His-Genträger eingehend und kritisch evaluiert werden. Der Leser sei noch einmal darauf hingewiesen, dass die meisten Genträger in Deutschland mit einer CF-auslösenden CFTR-Mutation auf dem einen Allel und p.Arg117His-7 T auf dem anderen Allel klinisch gesund sind (s.o.). Bei der Gruppe von Männern mit CBAVD lässt sich die Infertilität post festum nicht durch die Gabe von Ivacaftor beseitigen.

Das Hauptproblem bei der praktischen Anwendung der Therapie mit Ivacaftor liegt in der Wechselwirkung mit anderen Medikamenten $[45,50]$. Ivacaftor wird in der Leber von CYP3A4 und CYP3A5 des Cytochrom 450 Systems verstoffwechselt. Für die Praxis bedeutsam ist die gleichzeitige Anwendung von CYP3AInhibitoren oder CYP3A-Induktoren. Makrolid-Antibiotika und Azol Antimykotika sind CYP3A-Inhibitoren, die zur Behandlung von nicht-viralen Atemwegsinfektionen bzw. allergischer bronchopulmonaler Aspergillose bei Mukoviszidose häufig eingesetzt werden. Beim Einsatz dieser Medikamente ist die wöchentliche Dosis von Ivacaftor zu reduzieren. Andererseits wird die Wirksamkeit von Ivacaftor herabgesetzt, wenn gleichzeitig ein CYP3A-Induktor verordnet wird. Für die CF-Klinik relevante CYP3A-Induktoren sind Glukokortikoide und Rifampicin. Wenn CF-Patienten wegen einer chronischen Atemwegsinfektion mit Mykobacterium avium-Komplex eine antibiotische Kombinationstherapie erhalten, zu der typischerweise Rifampicin gehört, ist auf die Behandlung mit Ivacaftor zu verzichten.

Das Kombinationspräparat aus $200 \mathrm{mg}$ Lumacaftor und $125 \mathrm{mg}$ Ivacaftor (Handelsname Orkambi ${ }^{\mathrm{TM}}$ ) steht in Deutschland seit dem 30.11.2015 zur Behandlung von p.Phe508del homozygoten CF-Patienten ab einem Alter von 12 Jahren zur Verfügung.
Lumacaftor ist ein starker CYP3A-Induktor und Ivacaftor ein schwacher CYP3A-Inhibitor. Dementsprechend ist ein anderes Spektrum an Wechselwirkungen bei Kombinationstherapie mit Lumacaftor/Ivacaftor als bei Monotherapie mit Ivacaftor zu erwarten. Die gleichzeitige Anwendung von Lumacaftor/Ivacaftor und Rifampicin wird nicht empfohlen, aber bei bereits laufender Behandlung mit Lumacaftor/Ivacaftor können das Makrolid-Antibiotikum Clarithromycin und die Azol-Antimykotika Itraconazol und Voriconazol ohne Dosisanpassung verordnet werden.

Die Einleitung der Therapie mit Ivacaftor oder Orkambi ${ }^{\mathrm{TM}}$ sollte bei kränkeren CF-Patienten ärztlich überwacht werden. Wenn die CFTR-Modulatoren wirksam sind, werden bei Beginn der Therapie zum ersten Mal im Leben des CF-Patienten in seinem Körper in bisher nicht bekanntem Ausmaß Sekrete mobilisiert und drainiert. Die Passage der Sekrete längs der Gallen- und Pankreasgänge kann mit starken Oberbauchschmerzen verbunden sein. Wenn Patienten bereits in ihrer Lungenfunktion deutlich eingeschränkt sind (FEV1 $<40 \%$ des Solls) und/oder große Mengen an Sekret in ihren Atemwegen produzieren, muss durch aktive oder passive atemphysiotherapeutische Maßnahmen Sorge getragen werden, dass die Sekrete vollständig drainiert und expektoriert werden. Die Blockade größerer Atemwege mit Sekret aufgrund insuffizienter Drainage ist wegen der unmittelbaren Auswirkungen auf den Gasaustausch und die intrapulmonalen Drucke unbedingt zu vermeiden. Diese kritische initiale Phase dauert nach Kenntnis des Autors nicht länger als drei Tage an. Weiterhin ist wichtig zu wissen, dass das im Orkambi ${ }^{\mathrm{TM}}$ enthaltene Lumacaftor bei zahlreichen Patienten in der ersten Woche der Behandlung eine reversible Obstruktion der Atemwege auslöst, die mit Dyspnoe einhergehen kann $[44,45]$. Eine symptomatische Behandlung mit einem Bronchodilator ist angezeigt, aber nicht bei jedem Patienten erfolgreich. Die Ursache dieses Off-target-Effekts ist zurzeit noch unbekannt.

Weitere detaillierte Angaben zu Dosierung und Art der Anwendung (Einnahme der Tabletten mit einer fetthaltigen Speise), empfohlenen Kontrolluntersuchungen, Nebenwirkungen, Wechselwirkungen mit anderen Arzneimitteln, Pharmakodynamik und Pharmakokinetik von Ivacaftor und Lumacaftor/Ivacaftor finden sich in den Fachinformationen des Herstellers.

Der beträchtliche Zusatznutzen der Behandlung von CF-Patienten, die mindestens eine Typ-III-Mutation auf ihren CF-Chromosomen tragen, mit dem CFTR-Potentiator Ivacaftor wurde in der Literatur und klinischen Studien eindrucksvoll belegt, sodass man für diese Gruppe sogar von einem Quantensprung in der Lebensqualität sprechen kann $[4,29-32,36]$. Die Therapie mit Ivacaftor kann für diese Patientengruppe ohne Einschränkungen empfohlen werden, soweit keine patientenbezogenen Komorbiditäten oder Therapien als Kontraindikation dem entgegenstehen.

Der generelle Nutzen der Therapie von p.Phe508del homozygoten Patienten mit Lumacaftor/Ivacaftor kann zurzeit noch nicht eindeutig beurteilt werden. Zum einen wurde noch nicht der Nachweis geführt, dass Lumacaftor/Ivacaftor beim Patienten in vivo den Basisdefekt abschwächt oder sogar beseitigt, und zum anderen wurde nur bei einem Fünftel der Studienteilnehmer eine absolute Zunahme der FEV1 von $8 \%$ und mehr beobachtet [45], die bei der Behandlung von Typ-III-CF-Mutationsträgern mit Potentiator die Regel ist [29-32]. Das CF-Team an der Medizinischen Hochschule Hannover hat sich daher auf ein differenzierteres Vorgehen für die Verordnung des Kombinationspräparats Orkambi ${ }^{\mathrm{TM}}$ verständigt ( $\mathbf{A b b . 3}$ ). Die klinischen Studien wurden an Patienten mit 40\%-90\% des Solls an FEV1 durchge- 


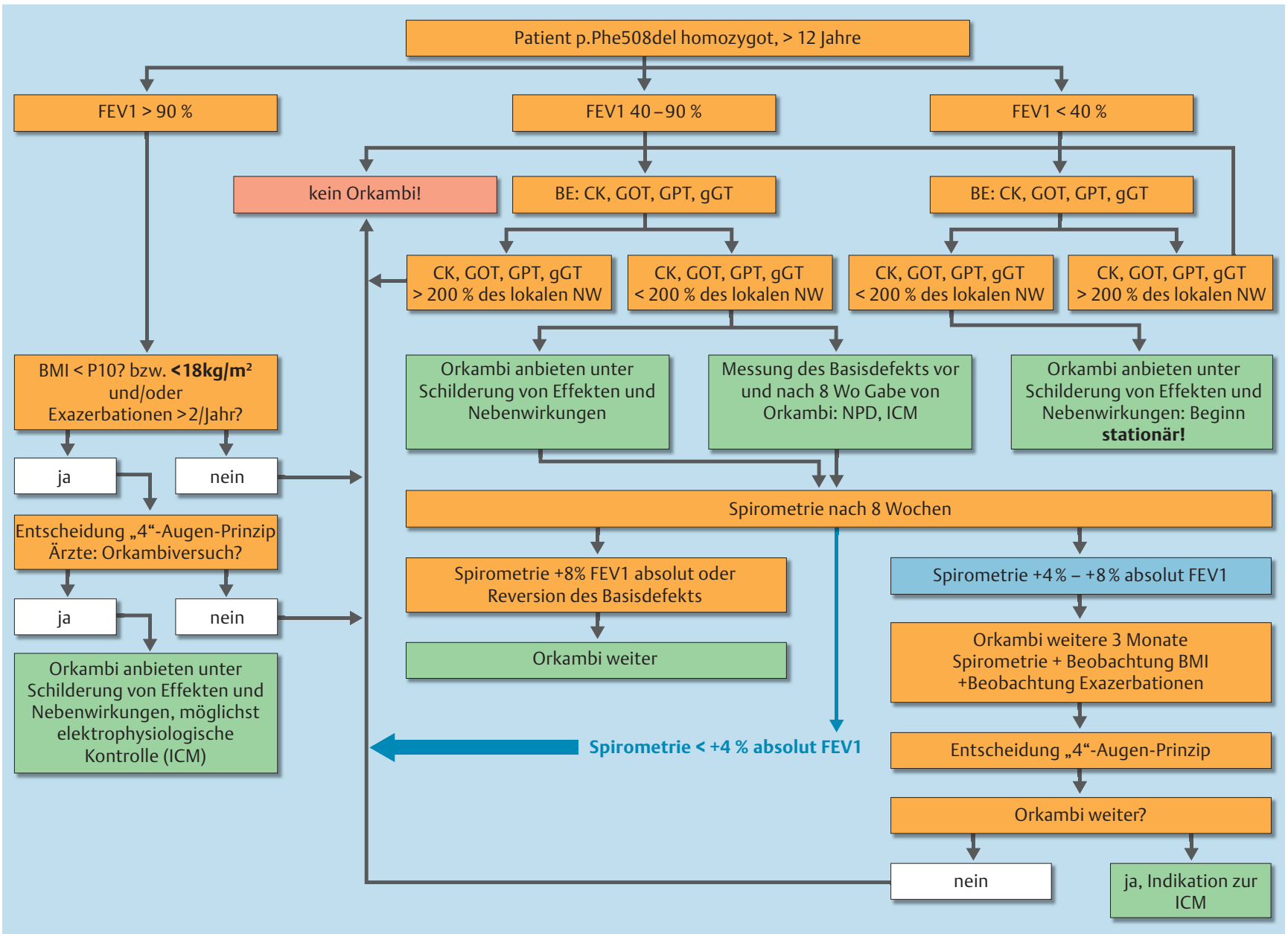

Abb.3 Konsentierter Entscheidungsbaum des CF-Teams an der Medizinischen Hochschule Hannover zur Verordnung von Orkambi ${ }^{\mathrm{TM}}$. Die Indikation zur Gabe von OrkambiTM wird bei p.Phe508del homozygoten CF-Patienten mit einer FEV1 von $40 \%-90 \%$ des Solls evaluiert, wenn alle Serumwerte für die Kreatinkinase CK und die Leberenzyme GOT, GPT und y-GT um weniger als das zweifache der oberen Normgrenze erhöht sind.

führt. Daher werden wir vorerst nur klinisch symptomatischen p.Phe508del-Homozygoten die Behandlung mit Orkambi ${ }^{\mathrm{TM}}$ anbieten und nach 8 Wochen den Nutzen anhand der Lungenfunktion und/oder der Wirkung auf den Basisdefekt prüfen. Bei einem vergleichsweise geringen Zugewinn von 4-8 absoluten Prozentpunkten an FEV1 entscheiden mindestens zwei CF-Ärzte über Fortführung oder Abbruch der Therapie. Patienten mit altersnormaler Spirometrie erhalten Orkambi ${ }^{\mathrm{TM}}$ nur, wenn der individuelle Wirknachweis am Basisdefekt mit NPD und/oder ICM nachgewiesen wurde. CF-Patienten im Stadium IV mit einer FEV1 $<40 \%$ des Solls könnten am stärksten von dem mit Orkambi ${ }^{\mathrm{TM}}$ erzielten Zugewinn an Lungenfunktion profitieren. Gleichzeitig ist bei dieser Patientengruppe die Gefahr am größten, dass sie die initiale Phase der Bronchusobstruktion und/oder massiven Sekretmobilisierung nicht autonom beherrschen. Deshalb werden wir bis auf weiteres die Behandlung von p.Phe508del-Homozygoten im Stadium IV nur stationär beginnen.

Kalydeco $^{\mathrm{TM}}$ und Orkambi ${ }^{\mathrm{TM}}$ werden im Hochpreissegment vertrieben. Beide Medikamente gehören zu den teuersten Arzneimitteln in Deutschland mit Jahrestherapiekosten im sechsstelligen Euro-Bereich. Die täglichen Arzneimittelkosten für eins dieser beiden Medikamente übersteigen die Erlöse für die stationäre Behandlung von CF-Patienten, die Kalydeco ${ }^{\mathrm{TM}}$ oder Orkambi ${ }^{\mathrm{TM}}$ erhalten. Unerwartete Komplikationen, pulmonale Exazerbationen oder die antimikrobielle Suppressionstherapie machen häu- fig stationäre Aufenthalte von Mukoviszidosepatienten notwendig. Die Krankenhäuser sind daher auf das NUB-Verfahren gemäß $\S 6$ Abs. 2 KHEntgG angewiesen, um von den Kostenträgern die benötigten Zusatzentgelte zu erhalten. NUB-Anträge für Kalyde$\mathrm{Co}^{\mathrm{TM}}$ wurden bisher bewilligt, über Zusatzentgelte für Orkambi ${ }^{\mathrm{TM}}$ wird 2016 zum ersten Mal entschieden.

\section{Aktuelle Entwicklungen}

\section{Präklinische Forschung zur CFTR-Modulation}

Ein CFTR-Potentiator lässt sich konzeptionell einfacher als ein CFTR-Korrektor entwickeln. Ein Potentiator soll Störungen in der Regulation und Aufbau des Ionenkanals beseitigen. Daher spielen nur die Affinität und Spezifität der binären Wechselwirkung des Potentiators mit der CFTR-Mutante eine entscheidende Rolle. Ein CFTR-Korrektor muss hingegen Faltung, posttranslationale Reifung und intrazelluläres Trafficking der CFTR-Mutante korrigieren. Nach der stufenweise ko-translationalen Faltung am endoplasmatischen Retikulum [44] tritt CFTR posttranslational mit Hunderten von Proteinen in Kontakt, bevor der Zielort ,Apikalmembran' erreicht ist [51]. Das CFTR ,Interaktom' in der Bronchialepithelzelle setzt sich aus über 600 Proteinen zusammen, wovon 62 Proteine nur Wechselwirkungen mit Wildtyp CFTR und 208 Proteine nur Wechselwirkungen mit p.Phe508del CFTR 
eingehen [51]. Diese hohe Zahl an Interaktionen mag die Ursache sein, warum sich die Faltungsmutante Phe508del CFTR so schwer korrigieren lässt.

Die ko-translationale Faltung von CFTR am endoplasmatischen Retikulum erfolgt stufenweise, und aus Zellkulturuntersuchungen wissen wir, dass sowohl bei der initialen Faltung der NBD1, bei der anschließenden Kontaktbildung der NBD1 mit den Membrandomänen und bei der abschließenden Faltung der NBD2 mit Korrektoren eingegriffen werden muss, um eine regelrechte Faltung von Phe508del CFTR zu gewährleisten [41]. Dementsprechend benötigt man auch drei Klassen an Korrektoren, um ein normal gefaltetes stabiles Phe508del CFTR-Protein zu generieren. Lumacaftor ist ein Klasse-I-Korrektor. Über Kombination von Lumacaftor mit einem Klasse-II-Korrektor ließ sich die Ausbeute an korrekt prozessiertem Phe508del CFTR um ein Mehrfaches steigern [52].

Phe508del CFTR ist eine thermolabile Mutante. Wenn man aber das Ribosom manipuliert und die Synthese des naszierenden Phe508del CFTR verlangsamt, bilden sich Wildtyp-ähnliche thermostabile Konformationen aus. In Kombination mit Lumacaftor wurde an primären humanen Bronchialepithelzellen 50\% der Aktivität von nativem Wildtyp CFTR erzielt [53]. Diese In-vitroDaten sind ein ,proof of principle‘, dass sich der Basisdefekt bei p.Phe508del-Homozygotie beseitigen lässt.

Die Akkumulation von fehlgefaltetem thermolabilem Phe508del CFTR führt zur chronischen Aktivierung von Chaperonen und mündet in einer globalen Störung der zellulären Proteinhomöostase [54]. Die Mukoviszidose der p.Phe508del-Homozygoten ist somit nicht nur eine Ionenkanalerkrankung, sondern gleichzeitig eine Erkrankung der Zelle wie bei der Z-Variante des alpha-1-Antitrypsinmangels. Diese sich selbstunterhaltende proteotoxische Krise lässt sich durch Blockade des zentralen Hitzeschockfaktors 1 (HSF1) bekämpfen. In Anwesenheit eines HSF1-Inhibitors verdoppelte Lumacaftor die Chloridsekretion in Organoiden von p.Phe508del homozygoten CF-Patienten [54].

Zu den zahlreichen durch Phe508del CFTR ausgelösten Störungen der Proteinhomöostase gehört die Aktivierung der Transglutaminase, die Proteine zu Aggregosomen vernetzt [55]. Cysteamin hemmt die Transglutaminase. Wenn p.Phe508del homozygote CF-Mäuse, Zelllinien, primäre Nasalepithelzellen und schließlich auch CF-Patienten über Wochen mit Cysteamin zusammen mit dem Genistein-verwandten Naturstoff Epigallocatechingallat (EGCG) behandelt wurden, wurde konsistent in allen Systemen Phe508del CFTR in der Apikalmembran und ein vermehrter apikaler Chloridtransport beobachtet [55]. Cysteamin ist ein zugelassenes ,orphan drug', EGCG ein frei erhältliches Nahrungsergänzungsmittel. Damit eröffnet sich die Option, einen kostengünstigen CFTR-Korrektor in die klinische Anwendung zu bringen.

Die präklinische Forschung lieferte außerdem plausible Daten, warum die Kombinationstherapie mit Ivacaftor/Lumacaftor nicht die hoch gesteckten Erwartungen erfüllt hat: Vorinkubation p.Phe508del homozygoter Zellen mit Ivacaftor reduzierte den Korrekturerfolg der Klasse-I-Korrektoren Lumacaftor und VX661, weil Ivacaftor apikales Phe508del CFTR-Protein in eine Konformation überführt, die schnell wieder abgebaut wird [56,57]. Diese unerwünschte Wechselwirkung zwischen Potentiator und Korrektor ist aber keine allgemeine Eigenschaft von CFTR-Potentiatoren. Mittlerweile wurden Moleküle identifiziert, die in nanomolaren Konzentrationen den Phe508del CFTR-Kanal aktivieren, ohne dass die Effizienz von Lumacaftor und VX-661 beeinträchtigt wird [58]. Diese Moleküle sind jedoch inaktiv gegen- über Gating-Mutanten wie Asp551 CFTR, was auf einen anderen Wirkungsmechanismus als bei Ivacaftor hinweist [58].

\section{Klinische Studien}

Die derzeit laufenden Studien sind in erster Linie darauf ausgerichtet, bereits bekannte CFTR-Modulatoren bei jüngeren oder schwerer betroffenen Patienten oder bei Patienten mit anderen CFTR-Mutationsgenotypen auf ihre Wirksamkeit zu prüfen:

- Ataluren bei CF-Genträgern für eine Stopp-Mutation, die nicht mit einem Aminoglykosid inhalieren

- Lumacaftor/Ivacaftor bei p.Phe508del homozygoten Patienten (a) im Alter von 6-11 Jahren oder (b) mit schwerer Lungenerkrankung

- Klasse-I-Korrektor VX661 /Ivacaftor bei compound heterozygoten CF-Patienten (>12 Jahre) mit p.Phe508del auf dem einen CFTR-Allel und (a) p.Phe508del oder (b) einer funktionslosen Klasse-I- oder Klasse-II-Mutation oder (c) einer Klasse III ,Gating'-Mutation oder (d) einer Klasse-IV- oder Klasse-V-Mutation mit CFTR-Restfunktion auf dem anderen CFTR-Allel.

Es gibt allerdings auch Novitäten: Die Mutation p.Phe508del soll in den Atemwegen über Inhalation mit einem chemisch stabilisierten Antisense-Oligonukleotid korrigiert werden [59]. Riociguat, bekannt als Stimulator der löslichen Guanylatzyklase [60], wird nach erfolgversprechenden Versuchen in vitro auf seine Wirksamkeit als CFTR-Modulator in vivo geprüft werden.

Daneben werden Ansätze verfolgt, mit Stabilisatoren des CFTRProteins oder antinflammatorischen Substanzen die Wirkung von Korrektoren und Potentiatoren zu verstärken. N91115, ein Inhibitor der S-Nitrosoglutathionreduktase, reduziert die Spiegel an proinflammatorischen Mediatoren und konnte in präklinischen Modellen die Wirkung von CFTR-Modulatoren auf Phe508del CFTR verstärken und verlängern [61]. Dieses Konzept wird in einer Studie an p.Phe508del homozygoten Patienten geprüft werden, die regelmäßig Orkambi ${ }^{\mathrm{TM}}$ einnehmen.

\section{Prävention von CF-Morbidität}

2016 wird bundesweit das Neugeborenenscreening auf Mukoviszidose eingeführt. Bei Geburt sind die Atemwege des CF-Patienten noch normal. Ivacaftor ist zur Behandlung von CF-Patienten mit einer ,Gating“-Mutation ab einem Alter von zwei Jahren zugelassen. An dieser kleinen Gruppe werden wir in den nächsten Jahren lernen, ob die Dauertherapie mit einem CFTR-Modulator den Basisdefekt so nachhaltig abschwächt, dass sich die Sekundärveränderungen an den Atemwegen und am Gastrointestinaltrakt verhüten lassen. Der intrauterine Verschluss des Vas deferens wird sich nicht rückgängig machen lassen, aber der intrauterin und postnatal ablaufende Umbau des Pankreas sollte sich beeinflussen lassen. Von CF-Kleinkindern mit p.Gly551Asp wurde berichtet, dass sie unter der Gabe von Ivacaftor wieder exokrin pankreassuffizient wurden. Zum jetzigen Zeitpunkt ist die Hoffnung nicht unbegründet, dass sich unter der Dauertherapie mit Ivacaftor bei den Patienten mit ,Gating'-Mutation eine altersnormale Längen- und Gewichtsentwicklung und Lungenfunktion erzielen lässt.

Angesichts der geringen Zahl an Patienten, die bisher Ivacaftor über mehr als ein Jahr erhielten, lässt sich zurzeit noch nicht verlässlich abschätzen, in welchem Umfang mit unerwünschten Nebenwirkungen zu rechnen ist. Unter der Behandlung mit Ivacaftor wurde über Fälle von nicht kongenitaler Linsentrübung berichtet. Auch moderate Anstiege der Transaminasen im Serum als Zeichen einer klinisch inapparenten Leberzellschädigung wurden nicht selten beobachtet. Auch hat der Autor den subjek- 
tiven Eindruck gewonnen, dass sich bei einigen Patienten ab dem dritten Jahr die klinische Wirkung von Lumacaftor und/oder Ivacaftor abschwächt. Aus Langzeitbeobachtungen werden wir lernen, ob über Enzyminduktion oder ähnliche Mechanismen sich Pharmakokinetik und Pharmakodynamik der CFTR-Modulatoren verändern.

Krankheitsprävention ist ein hehres Ziel. Allerdings müssen die Maßnahmen bezahlbar bleiben. Die jetzige Behandlung von 200 p.Gly551Asp CF-Genträgern mit einem Medikament, das pro Jahr Therapiekosten von über 100000 Euro verursacht, fällt gesamtwirtschaftlich noch nicht ins Gewicht. Wenn allerdings alle p.Phe508del homozygoten Mukoviszidosepatienten in Deutschland, deren Krankheitsverlauf in der ,Qualitätssicherung Mukoviszidose ' dokumentiert wird, Orkambi ${ }^{\mathrm{TM}}$ als Dauertherapie erhielten, würden die Kostenträger 2016 für ein einzelnes Medikament viermal mehr zahlen, als Bund und Länder den fünf Standorten des Deutschen Zentrums für Lungenforschung in den Jahren 2016 - 2020 zur Verfügung stellen werden. Angesichts dieser finanziellen Dimension ist der Dialog zwischen Ärzteschaft, Patientenvertretern, Kostenträgern, Politikern und Industrie mit dem Ziel gefordert, dass im Sinne des Interessenausgleichs zwischen Solidargemeinschaft und einzelnem Patienten die Mutationstyp-spezifische ,Präzisionsmedizin‘ bezahlbar bleibt. Zwischen den Mitgliedsstaaten der Europäischen Union (EU) bestehen erhebliche Unterschiede in den gesundheitsökonomischen Ressourcen. Die EU sollte daher ein Regelwerk für die zulässigen Erlösmargen etablieren, damit in allen Mitgliedsländern Patienten mit seltenen Erkrankungen mit ,orphan drugs“ versorgt werden können, ohne dass die Ressourcen für die globale Gesundheitsversorgung der Bevölkerung nennenswert geschmälert werden.

\section{Danksagung}

Die Forschungsarbeiten des Autors zur molekularen Pathologie der Mukoviszidose und zur Etablierung der CFTR-Biomarker wurden finanziell unterstützt von der Deutschen Forschungsgemeinschaft (SFB 587, TP A9; SFB 621, TP C7; SFB 900, TP A2), dem Bundesministerium für Forschung und Technologie (Disease Area CF am Standort BREATH des DZL), dem Mukoviszidose e.V. (SIP CFTR_1_2009 und CFTR_3_2010) und der Deutschen Fördergesellschaft zur Mukoviszidoseforschung e.V.

\section{Interessenkonflikt}

Der Autor erhielt Honorare von Vertex Pharmaceuticals für Vorträge, Aufsätze und Beratertätigkeit.

\section{Literatur}

1 Ratjen F, Bell SC, Rowe SM et al. Cystic fibrosis. Nature Dis Primers 2015: 15010

2 Mall MA, Elborn JS, Hrsg. Cystic Fibrosis. ERS monograph 64. Wakefield, UK: Charlesworth Press; 2014

3 Sens B, Stern M, Hrsg. Qualitätssicherung Mukoviszidose 2011. Bad Honnef: Hippocampus; 2012

4 Tümmler B Hrsg. Mutation-specific therapies in cystic fibrosis - Current status and prospects. Bremen: Uni-Med; 2014

5 Riordan JR. CFTR function and prospects for therapy. Annu Rev Biochem 2008; 77: 701-726
6 Gibson LE, Cooke RE. A test for concentration of electrolytes in sweat in cystic fibrosis of the pancreas utilizing pilocarpine by iontophoresis. Pediatrics 1959; 23: 545-549

7 Sato K, Sato F. Defective beta adrenergic response of cystic fibrosis sweat glands in vivo and in vitro. J Clin Invest 1984; 73: $1763-1771$

8 Quinton P, Molyneux L, Ip W et al. $\beta$-adrenergic sweat secretion as a diagnostic test for cystic fibrosis. Am J Respir Crit Care Med 2012; 186 : $732-739$

9 Knowles M, Gatzy J, Boucher R. Relative ion permeability of normal and cystic fibrosis nasal epithelium. J Clin Invest 1983; 71: 1410-1417

10 Rowe SM, Clancy JP, Wilschanski M. Nasal potential difference measurements to assess CFTR ion channel activity. Methods Mol Biol 2011; 741: 69-86

11 Wilschanski M, Famini H, Strauss-Liviatan N et al. Nasal potential difference measurements in patients with atypical cystic fibrosis. Eur Respir J 2001; 17: $1208-1215$

12 Sermet-Gaudelus I, Girodon E, Sands D et al. Clinical phenotype and genotype of children with borderline sweat test and abnormal nasal epithelial chloride transport. Am J Respir Crit Care Med 2010; 182: 929936

13 De Jonge $H R$, Ballmann $M$, Veeze $H$ et al. Ex vivo CF diagnosis by intestinal current measurements (ICM) in small aperture, circulating Ussing chambers. J Cyst Fibros 2004; 03 (Suppl. 02): 159-163

14 Mall M, Hirtz S, Gonska T et al. Assessment of CFTR function in rectal biopsies for the diagnosis of cystic fibrosis. J Cyst Fibros 2004; 03 (Suppl. 02): 165-169

15 Derichs $N$, Sanz J, Von Kanel T et al. Intestinal current measurement for diagnostic classification of patients with questionable cystic fibrosis: validation and reference data. Thorax 2010; 65: 594-599

16 Dekkers JF, Wiegerinck $C L$, de Jonge HR et al. A functional CFTR assay using primary cystic fibrosis intestinal organoids. Nat Med 2013; 19: 939-945

17 Eckford PD, Ramjeesingh M, Molinski S et al. VX-809 and related corrector compounds exhibit secondary activity stabilizing active F508del-CFTR after its partial rescue to the cell surface. Chem Biol 2014; 21: 666-678

18 Linde L, Kerem B. Nonsense-mediated mRNA decay and cystic fibrosis. Methods Mol Biol 2011; 741: 137-154

19 Fan-Minogue H, Bedwell DM. Eukaryotic ribosomal RNA determinants of aminoglycoside resistance and their role in translational fidelity. RNA 2008; 14: 148 - 157

20 Lee HL, Dougherty JP. Pharmaceutical therapies to recode nonsense mutations in inherited diseases. Pharmacol Ther 2012; 136: 227-266

21 Kerem E, Hirawat S, Armoni $S$ et al. Effectiveness of PTC124 treatment of cystic fibrosis caused by nonsense mutations: a prospective phase II trial. Lancet 2008; 372: 719-727

22 Sermet-Gaudelus I, Boeck KD, Casimir GJ et al. Ataluren (PTC124) induces cystic fibrosis transmembrane conductance regulator protein expression and activity in children with nonsense mutation cystic fibrosis. Am J Respir Crit Care Med 2010; 182: 1262 - 1272

23 Kerem E, Konstan MW, De Boeck K et al. Ataluren for the treatment of nonsense-mutation cystic fibrosis: a randomised, double-blind, placebo-controlled phase 3 trial. Lancet Respir Med 2014; 2: 539-547

24 Moran 0, Zegarra-Moran 0 . A quantitative description of the activation and inhibition of CFTR by potentiators: Genistein. FEBS Lett 2005; 579: $3979-3983$

25 Van Goor F, Hadida S, Grootenhuis PD et al. Rescue of CF airway epithelial cell function in vitro by a CFTR potentiator, VX-770. Proc Natl Acad Sci U S A 2009; 106: 18825 - 18830

26 Eckford PD, Li C, Ramjeesingh $M$ et al. Cystic fibrosis transmembrane conductance regulator (CFTR) potentiator VX-770 (ivacaftor) opens the defective channel gate of mutant CFTR in a phosphorylation-dependent but ATP-independent manner. J Biol Chem 2012; 287: $36639-36649$

$27 \mathrm{Yu} \mathrm{H}$, Burton B, Huang $\mathrm{CJ}$ et al. Ivacaftor potentiation of multiple CFTR channels with gating mutations. J Cyst Fibros 2012; 11: 237-245

28 Van Goor F, Yu H, Burton B et al. Effect of ivacaftor on CFTR forms with missense mutations associated with defects in protein processing or function. J Cyst Fibros 2014; 13: 29-36

29 Accurso FJ, Rowe SM, Clancy JP et al. Effect of VX-770 in persons with cystic fibrosis and the G551D-CFTR mutation. N Engl J Med 2010; 363: $1991-2003$

30 Ramsey BW, Davies J, McElvaney NG et al. A CFTR potentiator in patients with cystic fibrosis and the G551D mutation. N Engl J Med 2011; 365: $1663-1672$ 
31 Davies JC, Wainwright CE, Canny GJ et al. Efficacy and safety of ivacaftor in patients aged 6 to 11 years with cystic fibrosis with a G551D mutation. Am J Respir Crit Care Med 2013; 187: 1219-1225

32 Davies J, Sheridan $H$, Bell $N$ et al. Assessment of clinical response to ivacaftor with lung clearance index in cystic fibrosis patients with a G551D-CFTR mutation and preserved spirometry: a randomised controlled trial. Lancet Respir Med 2013; 1: 630-638

33 Harrison MJ, Murphy DM, Plant BJ. Ivacaftor in a G551D homozygote with cystic fibrosis. N Engl J Med 2013; 369: 1280-1282

34 Hebestreit H, Sauer-Heilborn A, Fischer R et al. Effects of ivacaftor on severely ill patients with cystic fibrosis carrying a G551D mutation. J Cyst Fibros 2013; 12: 599-603

35 Graeber SY, Hug MJ, Sommerburg O et al. Intestinal Current Measurements Detect Activation of Mutant CFTR in Patients with Cystic Fibrosis with the G551D Mutation Treated with Ivacaftor. Am J Respir Crit Care Med 2015; 192: $1252-1255$

36 Rowe SM, Heltshe SL, Gonska T et al. Clinical mechanism of the cystic fibrosis transmembrane conductance regulator potentiator ivacaftor in G551D-mediated cystic fibrosis. Am J Respir Crit Care Med 2014; 190: $175-184$

37 De Boeck K, Munck A, Walker S et al. Efficacy and safety of ivacaftor in patients with cystic fibrosis and a non-G551D gating mutation. J Cyst Fibros 2014; 13: 674-680

38 Moss RB, Flume PA, Elborn JS et al. Efficacy and safety of ivacaftor in patients with cystic fibrosis who have an Arg117His-CFTR mutation: a double-blind, randomised controlled trial. Lancet Respir Med 2015; 3: $524-533$

39 Kälin N, Claass A, Sommer M et al. DeltaF508 CFTR protein expression in tissues from patients with cystic fibrosis. J Clin Invest 1999; 103: $1379-1389$

40 van Barneveld A, Stanke F, Tamm $S$ et al. Functional analysis of F508del CFTR in native human colon. Biochim Biophys Acta 2010; 1802: 1062 1069

41 Okiyoneda T, Veit G, Dekkers JF et al. Mechanism-based corrector combination restores $\triangle$ F508-CFTR folding and function. Nat Chem Biol 2013; 9: 444-454

42 Van Goor F, Hadida S, Grootenhuis PD et al. Correction of the F508delCFTR protein processing defect in vitro by the investigational drug VX809. Proc Natl Acad Sci U S A 2011; 108: 18843 - 18848

43 Clancy JP, Rowe SM, Accurso FJ et al. Results of a phase IIa study of VX809, an investigational CFTR corrector compound, in subjects with cystic fibrosis homozygous for the F508del-CFTR mutation. Thorax 2012; 67: $12-18$

44 Boyle MP, Bell SC, Konstan MW et al. A CFTR corrector (lumacaftor) and a CFTR potentiator (ivacaftor) for treatment of patients with cystic fibrosis who have a phe508del CFTR mutation: a phase 2 randomised controlled trial. Lancet Respir Med 2014; 2: 527 -538

45 Wainwright CE, Elborn JS, Ramsey BW et al. Lumacaftor-Ivacaftor in Patients with Cystic Fibrosis Homozygous for Phe508del CFTR. N Engl J Med 2015; 373: 220-231

46 He L, Kota P, Aleksandrov AA et al. Correctors of $\triangle \mathrm{F} 508$ CFTR restore global conformational maturation without thermally stabilizing the mutant protein. FASEB J 2013; 27: 536-545
47 Davis PB. Another Beginning for Cystic Fibrosis Therapy. N Engl J Med 2015; 373: 274-276

48 Jones AM, Barry PJ. Lumacaftor/ivacaftor for patients homozygous for Phe508del-CFTR: should we curb our enthusiasm? Thorax 2015; 70: $615-616$

49 Tümmler $B$. The stony road to phe508del CFTR pharmacotherapy: smoothing the first rock. Lancet Respir Med 2014; 2: 508-509

50 Wainwright CE. Ivacaftor for patients with cystic fibrosis. Expert Rev Respir Med 2014; 8: 533-538

51 Pankow S, Bamberger C, Calzolari D et al. $\triangle$ F508 CFTR interactome remodelling promotes rescue of cystic fibrosis. Nature 2015; 528: 510 516

52 Phuan PW, Veit G, Tan J et al. Synergy-based small-molecule screen using a human lung epithelial cell line yields $\triangle$ F508-CFTR correctors that augment VX-809 maximal efficacy. Mol Pharmacol 2014; 86: $42-51$

53 Veit G, Oliver K, Apaja PM et al. Ribosomal stalk silencing corrects the $\triangle$ F508-CFTR functional expression defect. PLoS Biology 2016 [im Druck]

54 Roth DM, Hutt DM, Tong $J$ et al. Modulation of the maladaptive stress response to manage diseases of protein folding. PLoS Biol 2014; 12 : e1001998

55 De Stefano D, Villella VR, Esposito $S$ et al. Restoration of CFTR function in patients with cystic fibrosis carrying the F508del-CFTR mutation. Autophagy 2014; 10: 2053-2074

56 Cholon DM, Quinney NL, Fulcher ML et al. Potentiator ivacaftor abrogates pharmacological correction of $\triangle$ F508 CFTR in cystic fibrosis. Sci Transl Med 2014; 6: 246ra96

57 Veit G, Avramescu RG, Perdomo D et al. Some gating potentiators, including VX-770, diminish $\triangle$ F508-CFTR functional expression. Sci Trans Med 2014; 6: 246ra97

58 Phuan PW, Veit G, Tan JA et al. Potentiators of Defective $\triangle$ F508-CFTR Gating that Do Not Interfere with Corrector Action. Mol Pharmacol 2015; 88: 791 - 799

59 Brinks V, Lipinska K, Koppelaar $M$ et al. QR-010 treatment for cystic fibrosis: Assessing the airway - mucus barrier in delivery. Ped Pulmonol 2015; 50 (Suppl. 41): 271

60 Leuchte HH, Behr J, Ewert R et al. Riociguat: stimulator of soluble guanylate-cyclase. New mode of action for the treatment of pulmonary arterial and non operable chronic thromboembolic pulmonary hypertension. Pneumologie 2015; 69: 135-143

61 Taylor-Cousar JL, Zemanick E, Salomon G. The pharmacokinetics of N9115, an inhibitor of S-nitrosoglutathione reductase, in cystic fibrosis patients. Ped Pulmonol 2015; 50 (Suppl. 41): 285-286

62 Dörk T, Dworniczak B, Aulehla-Scholz C et al. Distinct spectrum of CFTR gene mutations in congenital absence of vas deferens. Hum Genet 1997; 100: 365 - 377

63 Quittner AL, Buu A, Messer MA et al. Development and validation of The Cystic Fibrosis Questionnaire in the United States: a health-related quality-of-life measure for cystic fibrosis. Chest 2005; 128: 2347 2354

64 Rowe SM, Liu B, Hill A et al. Optimizing nasal potential difference analysis for CFTR modulator development: assessment of ivacaftor in CF subjects with the G551D-CFTR mutation. PLoS One 2013; 8: e66955 